\title{
Statistical and Perceived Diversity and Their Impacts on Neigh- borhood Social Cohesion in Germany, France and the Netherlands
}

\author{
Ruud Koopmans \\ WZB Berlin Social Science Center
}

\author{
Merlin Schaeffer \\ University of Cologne
}

\begin{abstract}
Please cite as: Koopmans, Ruud and Merlin Schaeffer. 2016. "Statistical and Perceived Diversity and Their Impacts on Neighborhood Social Cohesion in Germany, France and the Netherlands." Social Indicators Research 125(3):853-83.
\end{abstract}

\section{Abstract}

The question whether ethnic diversity is associated with declining social cohesion has produced much controversy. We maintain that more attention must be paid to cognitive mechanisms to move the debate ahead. Using survey data from 938 localities in Germany, France, and the Netherlands, we explore a crucial individual-level mechanism: perceptions of diversity. We not only consider perceptions of the amount, but also of the qualitative nature of diversity. By asking about various qualitative aspects of diversity, we test the cognitive salience of three explanations that have been proposed in the literature for negative diversity effects: out-group biases, asymmetric preferences and coordination problems. We show that all three mechanisms matter. Perceptions both mediate statistical diversity effects, and have important explanatory power of their own. Moreover, we are able to address the question to what extend the relationship of perceived diversity and neighborhood social cohesion varies across policy contexts. Based on assumptions in the literature about positive impacts of inclusive and culturally pluralist immigrant integration policy approaches, we hypothesize that ethno-cultural diversity is less negatively related to neighborhood social cohesion in more inclusive policy contexts. Our results provide partial support for this hypothesis as perceived diversity has a significantly stronger negative impact on neighborhood cohesion in Germany.

\section{Acknowledgements}

This research is part of the project "Ethnic Diversity, Social Trust and Civic Engagement", which is funded by the German Federal Ministry of Family Affairs, Senior Citizens, Women and Youth. We thank Joscha Legewie, Susanne Veit and members of the Department "Migration Integration Transnationalization" for helpful comments and ideas. Both authors have contributed equally to this article and the order of names is strictly alphabetical. Please direct all correspondence to: merlin.schaeffer@unikoeln.de 
Classical social scientists such as Durkheim, Weber and Simmel argued that social homogeneity is not necessary for modern societies to be integrated. Urbanization and industrialization not only erode traditional forms of social cohesion, but also produce new ones. Nevertheless, ethnic and cultural diversity seem to challenge the foundations of modern societies by reducing trust and cooperation. Various empirical studies have shown that ethnic and racial heterogeneity are associated with lower levels of support for welfare redistribution (e.g. Eger 2010), production of public goods (e.g. Alesina, Baqir, and Easterly 1999), trust (e.g. Gundelach and Traunmüller 2013), and membership in associations (e.g. Stolle, Soroka, and Johnston 2008). According to Putnam's (2007) influential study, even trust in people who are like oneself is reduced by ethnic diversity, so that people in diverse communities seem to hunker down.

Despite the large amount of evidence that finds negative effects of ethnic diversity, there are also studies that find no significant effects on generalized trust (e.g. Tolsma, van der Meer, and Gesthuizen 2009; Dinesen 2013), helping among neighbors (Mata and Pendakur 2014), the radius of generalized trust (Delhey, Newton, and Welzel 2011), or participation in associations (e.g. Gesthuizen, van der Meer, and Scheepers 2008). Two recent meta-analyses (van der Meer and Tolsma 2014; Schaeffer 2014, Ch. 2) show that the studies that fail to document negative diversity effects tend to focus on the relatively abstract notion of generalized trust, and on higher (especially national) levels of aggregation. But the large majority of studies focusing on more specific measures of trust and social cohesion and on smaller socio-spatial units such as neighborhoods tend to find negative diversity effects (see also Koster 2013).

Supportive and confuting studies have in common that they pay little attention to the cognitive mechanisms by which ethnic diversity affects social cohesion. Yet, statistical diversity will for the most part affect attitudes and behavior to the extent that it is perceived and experienced (e.g. Alba, Rumbaut, and Marotz 2005). The lack of attention for cognitive mechanisms has three important drawbacks. First, in the absence of evidence on cognitive mechanisms, the micro link be- 
tween the contextual demographic situation and individuals' tendencies to withdraw from public social life has not yet been firmly established. Second, while various reasons, which we will discuss in detail below, have been proposed for why diversity affects trust and cooperation, it is often impossible to disentangle them on the level of statistical diversity. Operationalizations of different aspects of diversity are not available in official statistics (e.g., diversity of the norms and values to which people adhere), or are too highly correlated to differentiate them (e.g., linguistic and ethnic diversity). Third, since cognitive perceptions and experiences are more malleable and variable than objective levels of diversity, a better understanding of their role may help to identify the conditions under which diversity may be more or less harmful for social cohesion.

To move the debate ahead in this direction, we explore in this paper the role of statistical as well as perceived diversity in explaining social cohesion on the neighborhood level in three European countries, Germany, France, and the Netherlands. As we show in more detail below, these countries differ significantly regarding access to citizenship rights for immigrants, multicultural policies, and public debates on immigration. We are thus able to address the question to what extent the relationship of perceptions of diversity to neighborhood social cohesion varies across policy contexts. In particular, we investigate whether diversity is more strongly associated with reduced neighborhood social cohesion in the more assimilationist policy contexts of France and Germany.

As dependent variables, we analyze five interrelated aspects of neighborhood social cohesion: trust in neighbors, neighborhood collective efficacy, reported social problems in the neighborhood, as well as connectedness to neighbors and satisfaction with the neighborhood. By using cognitive measures of different aspects of diversity, we are able to differentiate between varying explanations for diversity effects that have been proposed in the literature. In particular, we investigate the merits of theories on out-group biases, asymmetric preference distributions, and coordination problems. 


\section{THEORETICAL FRAMEWORK AND HYPOTHESES}

The debate on ethnic diversity began to receive widespread attention with Alesina et al.'s (1999) study, which showed that the proportion of tax money spent on education, trash disposal, and welfare declines with the racial diversity of metropolitan areas. For the European context, Eger (2010) has similarly shown that in Sweden higher levels of ethnic diversity are associated with declining support for welfare state spending. Recently, Stichnoth (2012) has provided further evidence from German panel data according to which ethnic diversity is related to lower levels of support for the unemployed.

But why should social cohesion suffer in ethnically diverse communities? We discuss three theoretical approaches to this question. The majority of studies refer to theories on biases against out-group members. Next to these approaches, collective choice theories suggest that lower levels of public goods provision might be due to the asymmetry of preferences in ethnically diverse communities. Other theories emphasize coordination problems due to cultural differences and the associated lack of shared language, meanings and practices.

\section{Out-Group Biases}

Explanations for ethnic diversity effects that are based on negative attitudes towards out-groups come in two variants: social identity and group threat theories. Many studies refer to social identity theory (Tajfel 1978; Tajfel and Turner 1986) in order to explain negative diversity effects. The basic argument is that since people favor others who are alike, they see out-group members as less trustworthy and are less likely to invest in public goods if out-group members will profit as well (e.g. Alesina, Baqir, and Easterly 1999). Out-group biases are also central to group threat theory, which states that people perceive or experience conflicts with other ethnic groups over economic resources and symbolic representations (e.g. Blalock 1967). These conflicts cause people to see members of other ethnic groups as economic and cultural threats and have been put forward as pos- 
sible explanations of diversity effects (e.g. Hou and $\mathrm{Wu} 2009$ ). In support of both social identity and group threat approaches, some studies have found the negative effect of ethnic diversity to be stronger for people who oppose racial mixing (Alesina and La Ferrara 2000), or who hold antiimmigration attitudes (Marschall and Stolle 2004).

\section{Shared Preferences}

An obvious condition for collective action in pursuit of public goods is that there exists a shared goal in the first place. Accordingly, some scholars have argued that diversity in the goods that peo-

ple value leads to under-provision of public goods in ethnically diverse communities (e.g. Kimenyi 2006). In addition, Page has argued from a social choice perspective that asymmetrically distributed preferences may erode trust because they are a [...] potential for disagreement [that] may create incentives to misrepresent how we feel. We may try to manipulate process and agenda, creating distrust and dislike (Page 2008, 239). In support of preference diversity as a mechanism, Ruttan (2006) finds more disagreement about collective resource management in culturally heterogeneous communities. Baldwin and Huber (2010) advance a preference-diversity interpretation for the negative effect of group-based economic inequality on collective goods provision, arguing that: Groupbased economic differences can lead to different group needs with respect to public goods, feelings of alienation or discrimination by some groups, different attitudes toward redistribution across groups, and different class identities by different groups (Baldwin and Huber 2010, 644). By contrast, Habyarimana et al. (2007) found no significant differences regarding preferences for various collective goods across individuals of different ethnic backgrounds in Kenya.

\section{Coordination Problems}

Other authors have emphasized the importance of a common cultural toolkit (Swidler 1986). A shared language, as well as commonly understood practices and interpretive schemata are in this 
view necessary to communicate the existence of shared preferences and to successfully coordinate the production of common goods (Habyarimana et al. 2007). This is also underlined by experimental studies, which consistently show how groups that are allowed to communicate solve social dilemmas at much higher rates (e.g. Jeffreys 2008). Yet, the evidence in support of this explanation of diversity effects is mixed. Kooij-de Bode, van Knippenberg and van Ginkel (2008) show that ethnically homogenous groups distribute information more efficiently. Some studies have found linguistic diversity to have superior predictive power compared to ethnic diversity (Anderson and Paskeviciute 2006; Desmet, Ortuño-Ortín, and Wacziarg 2012), but this result is not confirmed in Baldwin and Huber's (2010) cross-national study. More confuting findings come from Lancee and Dronkers (2011) and Schaeffer (2013), who found no effects of host-country language proficiency of immigrants in the Netherlands and Germany.

\section{Perceptions as Mediators}

The three theoretical approaches discussed above are all possible explanations for the macrodemographic ethnic diversity effect on social cohesion. We believe that what Alba, Rumbaut and Marotz (2005) noted for the study of prejudice also holds for the study of trust and cooperation: between the macro-sociological plane of demographic shift and the micro-level phenomenon of individual prejudice as registered in surveys lies perception (Alba, Rumbaut, and Marotz 2005, 902). Accordingly, those aspects of ethnic heterogeneity that are actually perceived by actors are the ones most likely to have an impact on their attitudes and actions. These perceptions are likely to be more than just reflections of the environment as measured by public statistics. The innumeracy approach highlights that perceptions are shaped by personal, selective, and unrepresentative experiences of one's environment (Sigelman and Niemi 2001; Wong 2007), as well as media exposure and individual emotional set-ups (Herda 2010). 
Among students of out-group biases and prejudice, the role of perceptions has been widely acknowledged. Alba, Rumbaut and Marotz (2005) find that perceived diversity - measured by estimates of the group sizes racial minorities in the USA - predicts negative attitudes on immigration and minorities, but their findings are not adjusted for any measures of statistical diversity (see also Kouvo and Lockmer 2013). Others do control for the actual size of the immigrant population and find that the perception of larger immigrant shares is significantly related to feelings of ethnic threat and prejudices (Semyonov, Raijman, and Gorodzeisky 2008; Hooghe and de Vroome 2013). The debate on trust and social cohesion has, however, hardly seen any discussion of perceptions. Partial exceptions are Stolle et al. (2008) and Laurence (2011), who employ ordinal measures based on respondents' indication whether the minority, or majority of persons living in their neighborhood were immigrants, and show a negative impact on trust and social cohesion. Yet, they treat this as an alternative measure of statistical diversity, and neither investigate how perceptions mediate statistical diversity nor in how far they are predictors in their own right.

All these studies use a purely numeric operationalization of perceived diversity in the form of estimates of the size of immigrant or minority populations. While the quantity of perceived diversity obviously matters, theorizing on social cohesion and intergroup relations suggests that qualitative aspects such as the degree of perceived intergroup conflict, linguistic diversity, and diverging values and preferences matter as well. However, purely numeric measures of perceived diversity do not allow one to distinguish between these different cognitive mechanisms that have been suggested as explanations for diversity effects.

In addition to a numeric operationalization of perceived diversity similar to the one used in previous studies, we therefore use various more qualitative measures of perceived diversity that pick up different proposed cognitive mechanisms. We develop three hypotheses on such mechanisms. Our first hypothesis is derived from social identity and group threat theories and refers to the extent to which individuals perceive conflicts with members of other groups: perceptions of conflict 
with members of other groups are negatively associated with measures of social cohesion (H1). The second hypothesis is derived from theories emphasizing asymmetric preferences, and states that perceptions of diversity regarding the values and norms that people hold are negatively associated with measures of social cohesion (H2). Language is central to theories emphasizing coordination problems, and therefore our third hypothesis is that perceptions of linguistic diversity are negatively associated with measures of social cohesion (H3). Partly these qualitative aspects will be reflected in numeric estimates of diversity, but in line with earlier research findings, we also expect the perceived quantity of diversity to have an independent impact: perceptions of numeric diversity are negatively associated with measures of social cohesion (H4).

Theoretically, all these mechanisms are supposed to apply to both natives and immigrants. Negative effects of ethnic diversity are assumed to be caused by mutual out-group biases and perceptions of threat across ethnic groups or by overall population characteristics such as linguistic and preference pluralism that affect people irrespective of their ethnic origin. In that, theories of ethnic diversity effects are different from those focusing on anti-immigrant prejudice and stereotyping, which assume, or at least empirically focus on, one-sided rejection or mistrust of minorities by the native majority population. To check whether our findings indeed hold across groups we will report results of separate analyses for natives and persons of immigrant origin.

Further, we formulate two hypotheses on the relationship between perceived and statistical diversity. Because perceived diversity lies between macro-demographic characteristics of the environment and individual attitudes and behavior, we hypothesize that perceptions mediate the effects of statistical ethnic diversity on measures of social cohesion (H5). However, we also expect that because of differential individual sensibilities to diversity, and varying exposure to environmental framing of diversity, e.g., by the media, perceptions of ethnic and cultural diversity have an independent effect on measures of social cohesion over and above that of statistical measures of diversity (H6). 


\section{Policy Impacts}

Several studies have investigated whether negative effects of ethnic diversity are reinforced within policy contexts that emphasize immigrants' assimilation to a dominant culture and render immigration and diversity negatively salient, or conversely whether they are mitigated in inclusive and multicultural policy contexts that frame diversity more positively. Research on anti-immigrant attitudes provides evidence of policy effects along these lines. Hopkins (2010) found that anti-immigrant sentiments in the US increased when rising immigration on the local level combined with debates in national politics and media in which immigration was problematized (similarly Schlueter and Davidov 2011 for Spain). In a similar vein, Helbling, Reeskens, and Stolle (2013) find that negative impacts of ethnic diversity are stronger in countries where immigration is a salient topic in political party programs. A few cross-national studies have investigated whether such policy effects can be generalized into the domain of social cohesion, measured in these studies by generalized trust. Two of these studies (Kesler and Bloemraad 2010; Hooghe 2007) find no effect of multicultural policies, in contrast to Crepaz (2006).

In all these studies, policies and debates are supposed to affect attitudes towards diversity and immigration by way of changes they cause in people's perceptions: policies and debates that favor assimilationist or anti-immigrant positions are seen as raising people's perceptions of diversity as a problem, whereas multicultural policies make it salient in more positive ways. However, none of these studies provides measures of such perceptions that could substantiate this reasoning.

Because our study includes detailed measures of perceptions of diversity, and three countries with very divergent political approaches to immigrant and diversity, we are in a position to address this issue more directly. Germany, France and the Netherlands differ significantly in terms of immigrant integration policies according to a number of sources. The Migrant Integration Policy 
Index (MIPEX) ${ }^{1}$ classifies countries according to the inclusiveness of their policies with regard to immigrants on a scale ranging between 0 and 100, the latter figure indicating an ideal-typical case in which immigrants can quickly and easily obtain fully equal rights. On the 2010 version of this scale, the Netherlands ranks among the top 5 among 34 countries (index score 68), just behind Canada $\left(72,3^{\text {rd }}\right.$ rank) and ahead of the United States $\left(62,9^{\text {th }}\right.$ rank), while Germany (57) and France (51) rank lower $\left(12^{\text {th }}\right.$ and $15^{\text {th }}$, respectively). Whereas the MIPEX index focuses on individual citizenship rights such as naturalization and anti-discrimination policies, Koopmans, Michalowski and Waibel's (2012) ICRI index also includes policies relating to how countries deal with cultural diversity. Examples include support for immigrant languages in schools and the media, political representation rights for immigrant associations, or allowance of expressions of cultural difference such as headscarves in public institutions. Measured on a scale ranging from -1 to +1 , with the latter indicating the most inclusive policies, the results are very similar to MIPEX, with the Netherlands (+.40) clearly ahead of Germany (-.12) and France (-.15). Cross-nationally comparable data on recent media debates on immigration are scarce, but a recent study of debates on Muslim immigration in Western Europe shows that the tone of these debates was significantly more negative in Germany compared to France and the Netherlands (Carol and Koopmans 2013; Vanparys, Jacobs, and Torrekens 2013).

From these comparisons, the Netherlands clearly emerges as the most inclusive political context, with relatively favorable scores on both policies and debates. Because inclusive and multicultural policies and debates are assumed to promote more positive evaluations of diversity, we expect that perceptions of diversity exert a more positive or at least less negative effect on neighborhood social cohesion in countries with more inclusive and multicultural policies and debatesin our case in the Netherlands (H7).

\footnotetext{
${ }^{1}$ See http://www.mipex.eu/countries, accessed 10 June, 2013.
} 


\section{DATA AND METHODS}

The analysis is based on the Ethnic Diversity and Collective Action Survey (EDCAS), which was conducted in 2009-2010 (Schaeffer et al., 2016). The overall data set is based on 10,200 standardized telephone interviews with participants who were at least 18 years of age. We focus on a subsample of these data of about 4,600 respondents residing in localities for which we were able to obtain neighborhood-level contextual data. ${ }^{2}$ The survey has a $26 \%$ oversample of persons with a migration background, defined as either being born abroad or having at least one parent who was born abroad. There is an additional $14 \%$ oversample persons with a Turkish migration background. In order to prevent unaffordable screening costs, these latter participants were not sampled via random-digit dialing as the other respondents but via their last names from telephone directories. The sample is stratified by 228 German, 495 Dutch, and 215 French neighborhoods across eight German, ten French, and nine Dutch cities and regions (the names of the cities are listed in Table A1 in the appendix). German neighborhoods correspond to local statistical districts, French and Dutch neighborhoods refer to five-digit, respectively four-digit postal code areas.

Since our data is clustered in 938 neighborhoods, and the analyses include explanatory variables on both the individual and neighborhood levels of analysis, we have a multilevel setup for which it is inappropriate to use standard regression techniques. Our multilevel analysis therefore relies on linear regression models with cluster-robust standard errors, which yield the advantage that the standard errors of context-level parameters are not underestimated (Angrist and Pischke 2009, 308). In contrast to random intercept models, cluster-robust standard errors assume no partic-

\footnotetext{
2 This limitation pertains only to Germany, where the number of cases in the full EDCAS sample is higher and where the sampling frame included many smaller cities and rural regions, for which official statistics provide no harmonized and hence comparable neighborhood-level data (c.f. Friedrichs and Triemer 2008).
} 
ular kind of within-cluster correlation nor a particular form of heteroscedasticity (Wooldridge 2003, 134), meaning that they do not rely on the assumption of homoscedasic errors on either the contextual or the individual level.

\section{Neighborhood Social Cohesion}

Following Chan et al. (2006: 290), but focusing on neighborhoods rather than whole societies, we understand the concept of social cohesion to encompass "attitudes and norms of trust, a sense of belonging, and the willingness to participate and help, as well as their behavioral manifestations." Because cumulative integration in the study of the relationship between diversity and social cohesion is hampered by the fact that studies often focus only on one particular aspect of cohesion, such as trust (see Schaeffer 2014; Van der Meer and Tolsma 2014), we analyze five indicators of different, but theoretically and empirically interrelated aspects of neighborhood social cohesion. To ensure that the area the questions refer to corresponds to people's everyday experiences, respondents were instructed that neighborhood refers to the area within roughly ten minutes walking distance from their home. To begin with, we use the same indicator of trust in neighbors that Putnam (2007) uses:

Please indicate on a scale from 0 (not at all) to 10 (fully), how much do you trust the people in your neighborhood?

Our second measure, which is closely related to trust, is collective efficacy, which was originally developed by Sampson, Morenoff and Earls (1999) to measure a community's capacity to act collectively to solve neighborhood problems. We measured collective efficacy with a scale consisting of two items. 
In neighborhoods there are different problems. Let me give you some examples:

On a public green space lies bulky waste. On a scale from zero to ten, how likely is it that people from your neighborhood would jointly try to find a solution?

In a dark alley several people have been mugged. On a scale from zero to ten, how likely is it that people from your neighborhood would jointly try to find a solution?

Our third measure, reported social problems in the neighborhood, goes back to Garofolo's (1981) work on the broken windows theory and to other work on neighborhood disorder (Xu et al. 2005). It serves as an indicator of failed collective action and resulting under-provision of neighborhood public goods. We use a scale of two items, which refer to the same public goods as those used for measuring collective efficacy. We assume that disorderly waste disposal and unsafety are indicative of a failure of informal social control and cooperative norms in the neighborhood.

How often do the following problems occur in your neighborhood? Never, rarely, sometimes, often or very often?:

Waste lying about?

Harassment or verbal abuse?

Our fourth and fifth measures capture the sense of belonging aspect that Chan et al. (2006) refer to, tapping respectively social connectedness to neighbors and overall satisfaction with the neighborhood:

Please indicate on a scale from 0 (not at all) to 10 (fully), how strongly do you feel connected to other people in your neighborhood? 
Everything considered, how would you evaluate your neighborhood as a place to live on a scale from 0 (very bad) to 10 (very good)?

In the first part of our analyses, we will analyze these indicators of neighborhood social cohesion separately. In later steps, we summarize them into a composite neighborhood social cohesion scale, which has a Cronbach's alpha value of .79.

\section{Statistical and Perceived Diversities}

Ethnic diversity is commonly measured by way of ethnic fractionalization indices. Because our data cover three countries with divergent statistical categorizations of ethnicity, we cannot compute such an index in a cross-nationally consistent manner. However, unlike the situation in the United States, where an important part of racial diversity is unrelated to recent immigration, in Western Europe ethnic diversity is almost exclusively derived from immigration. Consequently, correlations between ethnic diversity indices and measures of the immigrant population, such as the percentage of foreign born, are so high as to make the measures statistically indistinguishable (Schaeffer 2013). This is also true for the data set we use, in which for the German case the correlation on the city level between the foreign-born population and the ethnic fractionalization index is as high as .94.

We therefore operationalized statistical ethnic diversity in the 959 neighborhoods by way of the percentage of people of immigrant origin, which includes those who are themselves born abroad, as well as people who have at least one foreign-born parent. In France, official statistics provide no information on French-born citizens of foreign parentage. We therefore used the percentage of the foreign born multiplied by a correction factor of 1.91 , which is derived from the relation between the number of foreign born persons and the number of people of immigrant origin including the native-born on the city level in Germany and the Netherlands. The relation is very 
similar in these two countries (1.84 and 1.98 , respectively), and therefore constitutes a reasonable basis for France as well.

Because ethnic diversity and the percentage of immigrants are statistically indistinguishable in the European context the question arises what they pick up: true ethnic diversity effects or just the majority's rejection or distrust of immigrants? We deal with this issue in two ways. First, we systematically perform our analyses separately for natives and people of immigrant origin. If statistical diversity just reflects majority prejudices against immigrants, we should find that negative effects of the size of the population of immigrant origin on trust and other measures of neighborhood cohesion are limited to natives. By contrast, if the results truly reflect ethnic diversity effects, we should find similar patterns for people of native and immigrant origin. Secondly, we use various measures of perceived ethno-cultural diversity that allow us to distinguish between the mere share of immigrants and qualitative aspects of diversity (e.g. preference or linguistic diversity) and thus to operationalize cognitive mechanisms between statistical diversity and neighborhood social cohesion in a more precise manner.

We include four measures of different aspects of perceived diversity corresponding to hypotheses 1-4. The first cognitive mechanism is derived from social identity and group threat theories and taps perceived intergroup conflict. Because such a question needs to refer to a concrete outgroup, the question was phrased differently for immigrants and natives. The former were asked for experiences with natives, the latter for experiences with immigrants:

Some people have had unpleasant experiences with immigrants [with Germans/Dutch/French], others not. How is this for you? How often did you have unpleasant experiences with immigrants [with Germans/Dutch/French], for instance in the form of harassment or unfair treatment? Answer categories were never, rarely, sometimes, often, and very often. 
The next two items are derived from theories of asymmetric preferences and coordination problems and measure respectively perceived preference diversity and perceived linguistic diversity:

In some neighborhoods people are very different from each other; in others they are very similar. Please indicate on a scale from zero to ten how strongly the inhabitants of your neighborhood differ in the following respects:

In the values and norms they follow?

In the languages they speak in everyday life?

Finally, following earlier studies (e.g., Semyonov et al. 2008), we measure the quantitative aspect of diversity, perceived numeric diversity, by asking respondents to estimate the size of the population of immigrant origin in their neighborhood:

How high do you estimate the percentage of people of non-[German/French/Dutch] orginin in your neighborhood to be? With non- [German/Franch/Dutch] origin we mean people who were not born in [Germany/France/the Netherlands] or of whom at least one parent was not born in [Germany/France/the Netherlands]. Please give a percentage between 0 and 100.

Quantitative perception of diversity may be partly driven by qualitative perceptions of diversity. Separate analyses with perceived numeric diversity as the dependent variable show that people who perceive much conflict with members of other groups and a high degree of divergence regarding languages and preferences and values, indeed also estimate the number 
of immigrants to be higher. We therefore show our results predicting neighborhood cohesion by perceived diversity in two steps: first only including the three qualitative measures as predictors, and then adding perceived numeric diversity. Because our analyses show that the four measures are related in similar ways to neighborhood social cohesion, we test the mediating effect of perceived ethnic diversity postulated by hypothesis 5 relying on a perceived ethnocultural diversity scale using the predicted factor scores from an exploratory principalcomponents factor analysis.

\section{Control Variables}

On the neighborhood level, we control for possible differences between rural, suburban, and urban areas by controlling for population density. Because it is a matter of contestation in the literature to what extent ethnic diversity effects are due to socio-economic factors, we control for the socioeconomic status of the local community by including the unemployment rate. ${ }^{3}$ Similarly, perceptions of ethnic diversity may partly reflect perceptions of socio-economic inequality. We therefore also include perceived socio-economic diversity as a control variable, based on the question: How strongly do the inhabitants of your neighborhood differ in their income levels? Like the items measuring perceived ethnic diversity, it is measured on an eleven-point scale.

As further individual-level control variables, we include age, gender, level of education, employment status, years of residence in the neighborhood, home ownership, marital status, reli-

\footnotetext{
${ }^{3}$ We also considered average income as an additional socio-economic control variable. This variable is available on the city level in Germany. We performed a robustness check including average income across 55 German cities. Income does however not turn out to be a significant predictor of neighborhood social cohesion and its inclusion does not affect the significant negative coefficient of ethnic diversity.
} 
gious denomination, as well as immigrant origin. ${ }^{4}$ Descriptive statistics of all variables used in the analyses are displayed in the appendix in Table A2.

\section{RESULTS}

\section{Statistical Ethnic Diversity and Neighborhood Social Cohesion}

Before we analyze the role of perceptions of diversity, we first determine whether there are any effects of statistical ethnic diversity in the first place, and whether they occur in all three countries. Table 1 shows these effects separately for Germany, France, and the Netherlands for each of the five composite measures of neighborhood social cohesion plus the summary scale, controlling for the full range of neighborhood and individual-level variables (full results including control variables can be found in the Appendix, Tables A3-A5).

\footnotetext{
${ }^{4}$ We do not include household income as an additional indicator of socio-economic status - next to level of education, employment status, and home ownership - because of the familiar problem that this variable has a high number of missing values.

${ }^{5}$ Two of the five perception measures, those referring to preference and income diversity, have relatively high numbers of missing observations ( $12 \%$ and $15 \%$, respectively) mainly due to don't know answers. That respondents found these variables difficult to answer may to be due to the fact that the norm and values other people obey as well as others' income levels are difficult to observe. Because of these, and other less frequent missing values on other variables, we rely on multiply imputed data. In accordance with Graham, Olchowski and Gilreath's (2007), we use thirty multivariate imputations. Following Ender (2010), the imputation models include all variables used in any of the regressions. All estimations for sub-populations (such as separate regressions for the countries) rely on data that were imputed just for these populations.
} 
Table 1: Statistical Diversity as a Predictor of Neighborhood Social Cohesion across 938 German, Dutch and French Neighborhoods

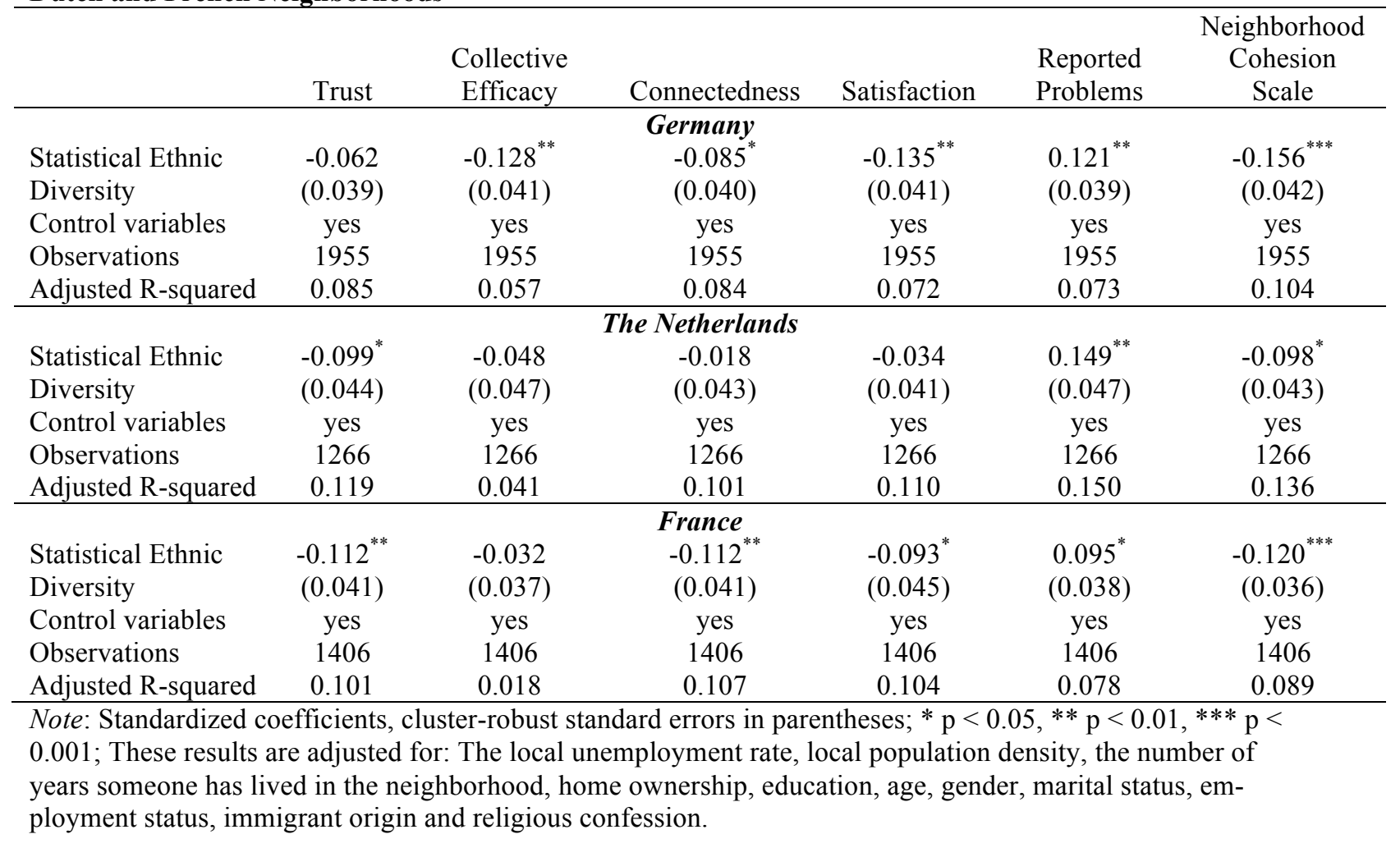

Reflecting the majority of existing studies, we find overall support for a negative effect of ethnic diversity on neighborhood social cohesion. In all three countries people report more social problems in diverse neighborhoods. Ethnic diversity significantly predicts lower trust in neighbors in France and the Netherlands, but not in Germany. By contrast, collective efficacy is only significantly lower in ethnically diverse neighborhoods in Germany. Connectedness to neighbors, and satisfaction with life in the neighborhood are significantly lower in diverse neighborhoods in Germany and France, but not in the Netherlands. Altogether, ten of the fifteen regression coefficients of ethnic diversity on the five measures of neighborhood social cohesion are significant and negative, while the signs of the remaining five are all in the expected direction. Not surprisingly, then, our summary scale of neighborhood social cohesion is consistently predicted negatively by ethnic di- 
versity in all three countries. Moreover, in a pooled three-country regression analysis (not shown here) all six dependent variables are predicted negatively and significantly by ethnic diversity.

Alternatively, we can analyze the data separately for natives and persons of immigrant origin rather than by country. These analyses - shown for the neighborhood cohesion scale in the first columns of Tables A6 and A7 (Appendix) - show that negative ethnic diversity effects cannot be reduced to fear or dislike of immigrants among natives. To the contrary, the pattern of effects is largely similar for natives and persons of immigrant origin. Both trust their neighbors less, and report more social problems and lower satisfaction levels in diverse neighborhoods. Natives also are significantly less connected to neighbors and have less confidence in neighborhood collective efficacy when they live in diverse neighborhoods. For both natives and persons of immigrant origin the overall neighborhood social cohesion scale is significantly negatively predicted by ethnic diversity. These results hold, as appendix Tables A6 and A7 show, while controlling for a range of variables on the neighborhood and individual levels of analysis.

\section{Perceived Ethnic Diversity and Neighborhood Social Cohesion}

Having established the relationship between statistical ethnic diversity and our dependent variables, we now investigate how perceptions of diversity can clarify the mechanisms behind statistical diversity effects. To this end we add our perceived diversity measures to the previous regression models for the neighborhood social cohesion scale (results for the five individual social cohesion items are very similar and available upon request). 
Figure 1: Statistical and Perceived Diversity as a Predictors of Neighborhood Social Cohesion across 938 German, Dutch and French Neighborhoods

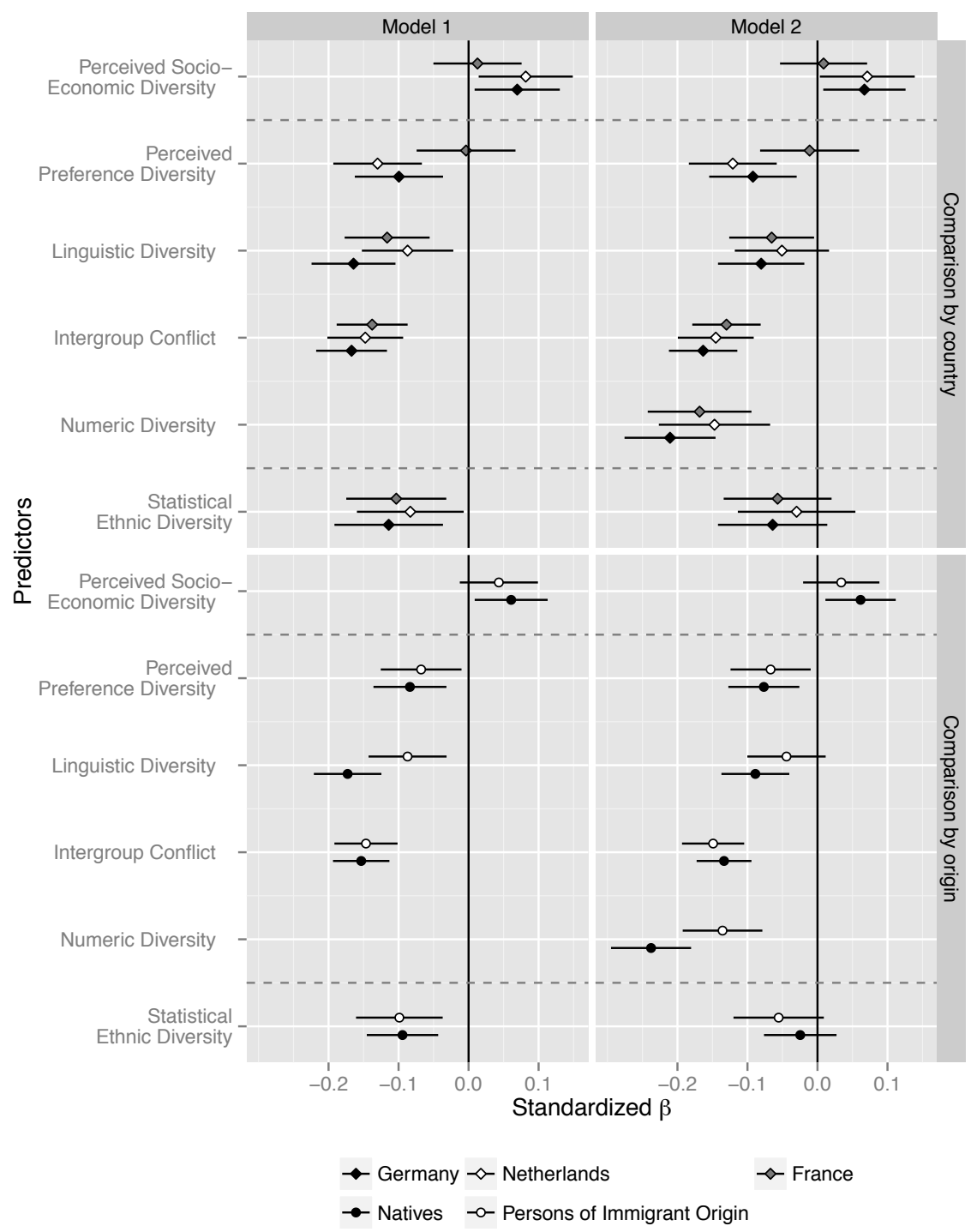

Note: Estimates are standardized coefficients from five OLS regressions with cluster-robust standard errors that control for: These results are adjusted for: The local unemployment rate, local population density, the number of years someone has lived in the neighborhood, home ownership, education, age, gender, marital status, employment status, immigrant origin and religious confession 
In Figure 1, we visualize point estimates and their 95\% confidence intervals - while controlling for the full range of background variables - for our four measures of perceived ethno-cultural diversity, perceived socio-economic diversity, and the remaining effect of statistical ethnic diversity. The upper panel of the figure shows results of separate regressions for each country, the lower panel for the contrast between natives and persons of immigrant origin. The results on the left-hand side of the figure only include the three qualitative measures of perceived ethnic diversity, the right-hand shows the results of models that additionally include perceived numeric diversity.

Focusing first on the left-hand side of the figure, we see that across the three countries, and for both natives and persons of immigrant origin, respondents who perceive a high degree of intergroup conflict report lower levels of neighborhood cohesion. In other words, they tend to trust their neighbors less and feel less connected to them, report more social problems, have less confidence in the capacity of neighbors to act together, and are overall less satisfied with their neighborhood. However, independent of such perceptions of direct group conflict, perceptions of diverging preferences, norms and values also matter. Except in France, those who perceive strongly divergent norms and values in their neighborhood display lower levels of neighborhood social cohesion. Again, this result holds very similarly for people of native and immigrant origin. Perceptions of linguistic diversity, too, predict neighborhood social cohesion negatively. This is true in all three countries and for people of native as well as immigrant origin. However, the linguistic diversity effect is stronger for natives. This is probably due to the fact that persons of immigrant origin themselves often speak a minority language and are therefore less bothered - but still not entirely unbothered - with linguistic diversity.

The results therefore do not clearly favor one theoretical perspective over the other but rather show that there is independent empirical merit in explanations for negative diversity effects that emphasize social identities and group threat, coordination problems, and asymmetric preferences. Together, the perception measures linked to these perspectives raise the explained variance 
of our models considerably and reduce the size of the statistical ethnic diversity effects (see tables A6 and A7 in the Appendix), although the latter remain statistically significant throughout, as Figure 1 shows.

Statistical ethnic diversity becomes statistically insignificant in all models, however, when we additionally include (see the right-hand side of Figure 1) our measure of perceived numeric diversity. This variable is a strong and highly significant negative predictor of neighborhood social cohesion in all three countries, and for both persons of immigrant origin and natives. However, the association is clearly stronger for the latter. Nevertheless, a stronger quantitative perception of ethnic diversity - measured here for the European context by the estimated percentage of immigrants in the neighborhood - also has a consistent negative impact on persons of immigrant origin's trust in their neighbors, their levels of reported social problems, and so on. Together with the fact that perceptions of intergroup conflict as well as linguistic and preference diversity also affect persons of immigrant origin and natives in very similar ways, this is strong evidence that the negative effects of perceptions of diversity on neighborhood social cohesion are not the result of one-sided rejection, distrust and unease among natives, but of similar feelings of minorities towards natives. Moreover, the negative effects of perceived linguistic and numeric diversity for persons of immigrant origin suggest that heterogeneity within the immigrant population also contributes to lower neighborhood social cohesion. Our results may actually underestimate the degree to which perceptions of intergroup conflict contribute to lowering neighborhood social cohesion for persons of immigrant origin. Our measure of perceived intergroup conflict asked only about their negative experiences with natives, but additionally they may perceive conflicts with persons of other ethnic backgrounds in diverse neighborhoods.

Comparing the left and right panels of Figure 1 shows that including perceived numeric diversity reduces the effect sizes of the three qualitative measures of perceived diversity, particularly it halves the importance of linguistic diversity. This confirms our intuition that stronger qualitative 
perceptions of diversity are partly picked up by numeric diversity estimates. Nevertheless, most of the effects remain significant after introducing perceived numeric diversity.

All these results obtain moreover while controlling for the full range of neighborhood-level and individual-level control variables. Full results are shown in Tables A3-A7 in the appendix. Results for one control variable, namely perceived socio-economic inequality, are however shown in Figure 1, because this variable directly tests a competing perception-based explanation for reduced neighborhood cohesion. However, as Figure 1 shows, perceived income inequality is actually positively related to neighborhood social cohesion, and significantly so in France and the Netherlands, and for natives in the cross-country analysis. This is a surprising finding given that socioeconomic inequality has in the literature often been mentioned as a source of reduced social cohesion (Delhey and Newton 2005). However, our result parallels Putnam's (2007) finding - for which he does not offer an explanation - that neighborhoods' income GINI coefficient positively predicts trust in neighbors.

Two possibilities come to mind that might explain why people who perceive more income inequality in their neighborhood are more likely to trust and feel connected to their neighbors, and to have a positive view of neighborhood life. The first possibility is that most of the neighborhoods with low-income inequality are homogeneously poor neighborhoods. This is however not the case in our data, since the correlation between perceived income inequality and the neighborhood unemployment rate is close to zero $(\mathrm{p}=.02, \mathrm{~ns})$. The other possibility is that economically less well-off residents have a more favorable view of neighborhoods where there are also better-off people, whose cognitive capacities (e.g., leadership and communication skills) and material resources can help to maintain a healthy neighborhood life, compared to neighborhoods where they live among other socio-economically marginalized people. Conversely, more highly educated and economically well-off people may view neighborhood social inequality negatively, because it implies that there are many people in the neighborhood who are less educated and poorer than themselves. This inter- 
pretation is supported by the data, since additional analyses including interactions between perceived income inequality and education reveal that perceived income inequality only stands in a significant positive relation to neighborhood social cohesion among those with a low level of education, and becomes insignificant among those with medium and even more so among those with high levels of education (see Table A.9 in the appendix). Tolsma et al.'s (2009: 16) finding for Dutch neighborhoods that the effect of economic heterogeneity has a positive sign for those in lower income brackets and turns negative for those with above-average incomes is also in line with this interpretation.

We now turn to the relationship between statistical and perceived diversity. Hypothesis 5 referred to the mediating role of perceived diversity and finds prima-facie support in the fact that when the four indicators of perceived ethno-cultural diversity are included in the regressions, statistical diversity becomes statistically insignificant in all three countries and for both natives and immigrants. Moreover, all measures of perceived ethnic diversity are strongly and significantly predicted by statistical ethnic diversity, with the exception of perceived intergroup conflict for persons of immigrant origin (results available on request). This latter exception is related to the fact that we asked only about negative experiences with natives and not about experiences with other minority groups. Since natives are present in significant numbers in all neighborhoods, it is not surprising that negatives experiences of persons of immigrant origin with natives are uncorrelated with ethnic diversity.

To establish more firmly whether there is a significant mediation path, we performed a formal test in the form of a Sobel-mediation analysis, for which we use the composite perceived ethnic diversity scale. The results are displayed in Figure 2. Because we are dealing here with a multi-level mediation - namely a context variable, statistical diversity, which is mediated by an individual-level variable, perceived diversity - we decomposed the scale scores (using empirical Bayes estimates) into a first part that varies between, and a second part that varies within localities. 
Following Zhang, Zyphur and Preacher's (2009) argument, only that part of perceived diversity that systematically varies between but not within localities can mediate context-level variables, which can lead to biased conclusions if ignored.

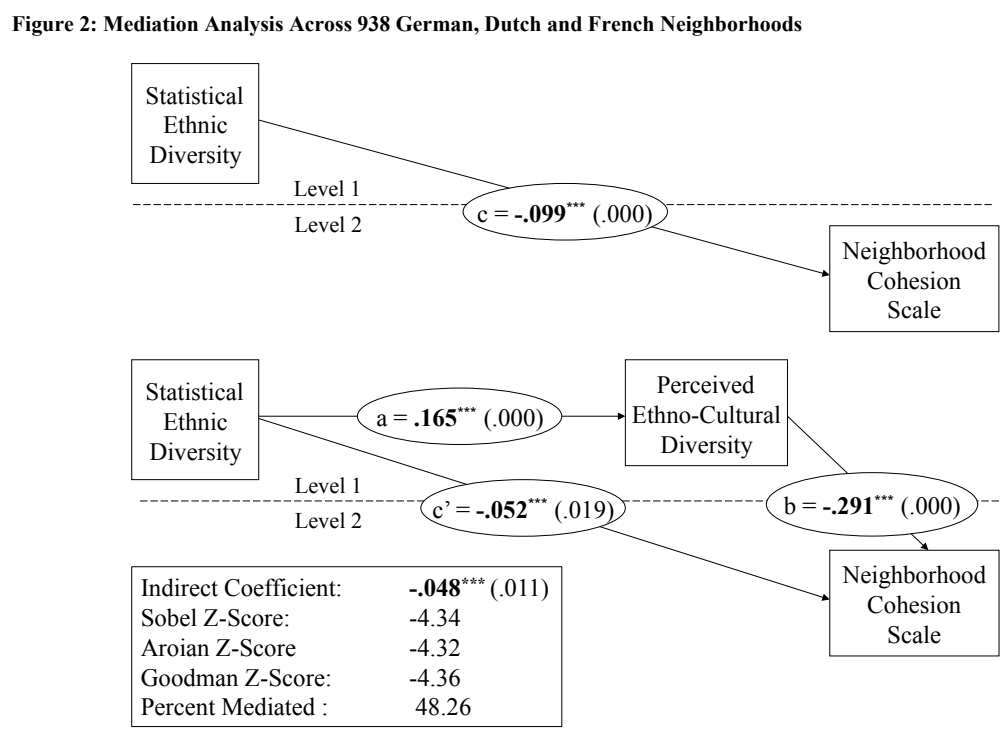

\begin{abstract}
Note: These standardized results are adjusted for: the local unemployment rate, local population density, the number of years someone has lived in the neighborhood, home ownership, education, age, gender, marital status, employment status, immigrant origin, religious confession, within-neighborhood perceptions of ethno-cultural diversity, and country differences.
\end{abstract}

The figure shows that in line with hypothesis 5 , statistical diversity effects are highly significantly mediated (at $\mathrm{p}<.001$ ) on the cognitive level by perceived diversity. Overall, the perceived ethno-cultural diversity scale mediates almost half (48\%) of the negative relation between statistical ethnic diversity and neighborhood social cohesion. ${ }^{6}$ Unlike the results displayed in Figure 1, the

${ }^{6}$ Because few studies have looked at perceived diversity as a mediator of statistical diversity, we do not have a benchmark to compare our result to. The two most relevant studies in this regard are Hooghe and De Vroome (2013) and Schlueter and Scheepers (2010). The former look at antiimmigrant attitudes, but do not find a significant direct effect of statistical diversity to begin with and therefore do not test the mediation path via perceived diversity. Schlueter and Scheepers do include 
direct path from statistical diversity to social cohesion remains significant. This is the result of the loss of information due to the pooling of natives and immigrants and the use of the perceived ethnocultural diversity scale rather than the four composite items. Performing parallel Sobel tests for the four mediation paths and separately for immigrants and natives is however not feasible given limitations of statistical power.

One might ask whether our interpretation that perceptions of ethnic diversity reduce neighborhood cohesion is correct, or whether alternatively people who are less trustful of and less connected to their neighbors tend to perceive their neighborhood as more diverse. A piece of evidence supporting our interpretation derives from a randomly assigned survey experiment that was integrated in the German part of our study. Using the well-know wallet question (if you would lose your wallet with money and your address in it in your neighborhood, how likely is it that it would be brought back to you with its content?) as the dependent variable, we could show that if the question was introduced with a priming sentence that contained a neutral reference to ethnic diversity, respondents - regardless of whether they were of native or immigrant origin - were significantly less likely to believe that their wallet would be returned, compared to respondents who had been assigned to a treatment referring to generational diversity or to no particular form of diversity at all (Koopmans \& Veit, 2014). This is clear evidence that perceptions of diversity causally affect trust in neighbors.

Hypothesis 6 states that the role of perceived diversity is not limited to mediating statistical diversity but has additional explanatory power in its own right. This we can show by comparing the adjusted $\mathrm{R}^{2}$ of the regressions with and without the four perceived diversity variables included (see Tables A3-A7 in the appendix). Hypothesis 6 can clearly be accepted because the inclusion of perceptions leads to a substantial improvement of the explanatory power in all three countries: from 10

perceived diversity as a mediator between statistical diversity and intergroup contact and perceived outgroup threat, but do not report how much of the effect is mediated. 
to 19 percent in Germany, from 14 to 21 percent in the Netherlands, and from 9 to 14 percent in France. Across the countries, the explained variance is raised from 14 to 23 percent among natives, and from 10 to 14 percent among immigrants.

Table 2 Comparison of Perceived Diversity Effects on Neighborhood Social Cohesion Between Germany, France and the Netherlands

\begin{tabular}{lccc}
\hline & Natives & Persons of Immigrant origin & All \\
\hline Perceived Ethno-Cultural Diversity & $-0.237^{* * *}$ & $-0.177^{*}$ & $-0.200^{* * *}$ \\
& $(0.061)$ & $(0.076)$ & $(0.042)$ \\
${ }^{*}$ GER & $-0.152^{*}$ & -0.054 & $-0.104^{*}$ \\
& $(0.076)$ & $(0.091)$ & $(0.053)$ \\
$* \mathrm{FR}$ & -0.018 & 0.061 & 0.020 \\
& $(0.080)$ & $(0.100)$ & $(0.054)$ \\
Control variables & yes & yes & yes \\
\hline Observations & 2373 & 2254 & 4627 \\
\hline Note: Fixed-effects robust standard errors in parentheses; * $\mathrm{p}<0.05, * * \mathrm{p}<0.01,{ }^{* * *} \mathrm{p}<0.001$ \\
These results are adjusted for: the number of years someone has lived in the neighborhood, home ownership, \\
education, age, gender, marital status, employment status, immigrant origin and religious confession.
\end{tabular}

As the final step in our analysis, we investigate the cross-national hypothesis 7 , which stated that perceived diversity has less negative effects on neighborhood social cohesion in countries with more inclusive immigrant integration policies, in our case in the Netherlands. The results presented in the upper panel of Figure 1 above do not point in this direction since the three countries' confidence intervals overlap for all estimates, although effects tend to be most strongly negative in Germany. We test hypothesis 7 more formally by regressing neighborhood social cohesion on the perceived diversity scale with interaction terms between perceived diversity and country. To exclude all possible sources of unobserved neighborhood-level heterogeneity, we use a neighborhoodfixed-effects specification, and further control for the full range of individual-level control variables. The coefficients for the interaction terms, displayed in Table 2, provide partial support for hypothesis 7 . While for immigrants there are no significant country differences, German natives' perceptions of diversity have a significantly more negative impact on neighborhood social cohesion compared to their Dutch counterparts. But French and Dutch natives do not differ noticeably in this regard. 


\section{CONCLUSIONS}

This study is to our knowledge the first to have investigated the relationship between ethnic diversity and social cohesion across localities in three different immigration countries, while also systematically comparing natives and persons of immigrant origin. We believe that by showing that the basic mechanisms connecting diversity to neighborhood social cohesion are highly similar across countries as well as for natives and persons of immigrant origin, our results have a greater generalization potential than earlier studies. In line with the majority of previous studies, we find negative effects of statistical ethnic diversity on each of our five measures of neighborhood social cohesion: trust, collective efficacy, connectedness, reported social problems, and overall satisfaction with neighborhood life. With few exceptions these effects are statistically significant in all three countries and apply to natives and persons of immigrant origin very much alike.

The second and most important way in which we have gone beyond existing studies has been to investigate the cognitive mechanisms behind diversity effects. Previous studies have always been vulnerable to the criticism that the relationships between contextual diversity and individual attitudes such as trust were not backed by evidence on micro-level mechanisms and therefore open to objections related to unobserved heterogeneity. We have argued that such mechanisms can be found in the form of individual perceptions of diversity. To the degree that statistically measured levels of diversity are actually perceived and experienced in everyday life, they can affect outcomes such as trust, efficacy or connectedness. In contrast to previous studies of perceptions of diversity, we go beyond a merely quantitative operationalization of perceived diversity. While we also incorporate the numeric measure of diversity that has been employed previously - the estimated percentage of immigrants - we also include three more qualitative measures of perceived diversity.

Importantly, these measures allow us to operationalize and test three different theoretical perspectives on the causes of negative diversity effects: social identity and group threat theory's 
emphasis on perceptions of intergroup conflict, as well as theories grounding problems of trust and collective action in asymmetric preferences, and in coordination problems due to linguistic differences. By controlling for people's perception of socio-economic (income) inequality we show that the effects of perceived ethno-cultural diversity are not a spurious result of underlying class inequalities. In fact, we show that perceived income inequality has effects that are opposed to those of ethno-cultural diversity, particularly among the lower educated and among immigrants. For these groups, the presence of cognitively and materially more resourceful groups raises trust in neighbors and confidence in the capacity of residents to solve neighborhood problems.

Overall, we find support for all three proposed theoretical mechanisms behind ethnocultural diversity effects. When people report negative experiences with out-groups, and perceive their neighbors as strongly diverse regarding their norms and values and regarding the languages they speak, they tend to have less trust in their neighbors, report more neighborhood problems, have less confidence in their local community's capacity to mobilize to do something about these problems, feel less connected to neighbors, and are less satisfied with neighborhood life. Importantly, these results hold for natives and persons of immigrant origin alike. Even though the latter are themselves the most important source of cultural diversity, they too trust their neighbors less and report more neighborhood problems if they perceive their local community to be more diverse and their neighbors to be more different from themselves. Theoretically, it is fully plausible that the three mechanisms are not simply additive, but rather complementary: not only can in-group versus out-group distinctions be based on perceived linguistic and value differences, but the other way around biases against out-groups may lead one to perceive linguistic and normative boundaries between groups more sharply. The investigation of such interactive effects is beyond the scope of this article, but might be a fruitful avenue for future research.

We were able to show that these cognitive mechanisms are indeed important mediators of statistical diversity. Inclusion of the perception variables substantially reduced the size of the re- 
gression coefficients for statistical ethnic diversity, which dropped below the level of statistical significance in all three countries and for immigrants and natives alike. A formal mediation test showed that overall about half of the effect of statistical ethnic diversity was mediated by our summary measure of perceived diversity. Perceptions are therefore an important mechanism by which statistical diversity affects social cohesion, certainly if one takes into account that we in all likelihood underestimate the strength of this mediation path because we had to pool natives and immigrants and use the combined social cohesion scale to have enough statistical power for a formal mediation test. Still, other mediating factors that are beyond the scope of this paper may be at work, too. The most frequently mentioned of these additional mediators are intergroup social contacts (e.g. Stolle, Soroka, and Johnston 2008). To the extent that these are less dense than intragroup contacts, diverse areas will either have a lower overall social network density or more segregated social networks, which both may harm trust and other aspects of social cohesion.

Beyond their role as mediators of statistical diversity, we showed that perceptions of diversity are also important predictors in their own right. Including perceptions in our models raised the explained variance of neighborhood social cohesion by more than sixty percent among natives and forty percent among immigrants. This is an important result if one considers that perceptions can be more easily affected by policies, political mobilization, and media coverage than the statistical composition of populations. Our results therefore suggest that future research should focus on factors that moderate the perception of diversity in order to better understand the conditions under which statistical ethnic diversity affects social cohesion.

As a first step in this direction, we investigated the potential impact of national policies on immigration and ethno-cultural differences on the effects of perceptions of diversity. Based on assumptions in the literature about positive impacts of inclusive and culturally pluralist policy approaches on interethnic relations, we hypothesized that, controlling for statistical levels of diversity, ethno-cultural diversity would be less negatively related to neighborhood social cohesion in the 
more inclusive policy context of the Netherlands, compared to the more assimilationist policy contexts of France and Germany.

Our results provide partial support for this hypothesis as the negative effect of perceptions of diversity was indeed stronger among natives in Germany compared to their counterparts in the Netherlands. However, French and Dutch natives, and persons of immigrant origin in all three countries, did not differ significantly. The reason for the more negative association of perceived diversity with neighborhood cohesion among German natives may be the particular way in which immigrants have been, and to some extent continue to be politically framed in Germany, namely in terms of nationality and foreignness. Even after the 2000 reforms of the naturalization law many immigrants, and even many of their German-born children, do not hold German citizenship and are depicted in public discourse as foreigners. By contrast, what France and the Netherlands have in common - in spite of very different approaches towards cultural and religious rights for immigrants (Koopmans et al. 2012) - is that they have long had inclusive naturalization regimes that have allowed most immigrants to become citizens. The stronger emphasis on foreignness in Germany and on common citizenship bonds in France and the Netherlands may be a reason why similar levels of perceived diversity are more strongly associated with feelings of distrust and unease among German natives than among their French and Dutch counterparts.

Clearly, additional cross-national studies are necessary to shed more light on these issues. Longitudinal studies investigating effects of policy changes within countries would have even greater potential, but have thus far hardly been implemented due to a lack of suitable panel studies. Above all, we believe that our study has demonstrated that, in view of their important role both as mediators of statistical diversity, and as explanatory factors in their own right, future research on the diversity-social cohesion nexus must pay central attention to perceptions of diversity, their determinants, and their effects. 


\section{REFERENCES}

Alba, Richard D., Ruben G. Rumbaut, and Karen Marotz. 2005. A Distorted Nation: Perceptions of Racial/Ethnic Group Sizes and Attitudes Toward Immigrants and Other Minorities. Social Forces 84 (2): 901-919.

Alesina, Alberto, Reza Baqir, and William Easterly. 1999. Public Goods and Ethnic Divisions. Quarterly Journal of Economics 114 (4): 1243-1284.

Alesina, Alberto, and Eliana La Ferrara. 2000. Participation in Heterogeneous Communities. Quarterly Journal of Economics 115 (3): 847-904.

Anderson, Christopher J., and Aida Paskeviciute. 2006. How Ethnic and Linguistic Heterogeneity Influence the Prospects for Civil Society: A Comparative Study of Citizenship Behavior. The Journal of Politics 68 (4): 783-802.

Angrist, Joshua David, and Jörn-Steffen Pischke. 2009. Mostly Harmless Econometrics: An Empiricist's Companion. Princeton: Princeton University Press.

Baldwin, Kate, and John D. Huber. 2010. Economic Versus Cultural Differences: Forms of Ethnic Diversity and Public Goods Provision. American Political Science Review 104 (4): 644-662.

Blalock, Hubert M. 1967. Toward a Theory of Minority-Group Relations. New York: Wiley.

Carol, Sarah, and Ruud Koopmans. 2013. Dynamics of Contestation over Islamic Religious Rights in Western Europe. Ethnicities 13 (2): 165-190.

Chan, Joseph, Ho-Pong To, and Elaine Chan. 2006. Reconsidering Social Cohesion: Developing a Definition and Analytical Framework for Empirical Research. Social Indicators Research 75(2): 273-302.

Crepaz, Markus. 2006. 'If You Are My Brother I May Give You a Dime!' Public Opinion on Multiculturalism, Trust, and the Welfare State. In Multiculturalism and the Welfare State. Recognition and Redistribution in Contemporary Democracies, edited by Keith Banting and Will Kymlicka, 92 117. Oxford: Oxford University Press.

Delhey, Jan, and Kenneth Newton. 2005. Predicting Cross-National Levels of Social Trust: Global Pattern or Nordic Exceptionalism? European Sociological Review 21 (4): 311-327.

Delhey, Jan, Kenneth Newton, and Christian Welzel. 2011. How General Is Trust in 'Most People'? Solving the Radius of Trust Problem. American Sociological Review 76 (5): 786 -807.

Desmet, Klaus, Ignacio Ortuño-Ortín, and Romain Wacziarg. 2012. The Political Economy of Linguistic Cleavages. Journal of Development Economics 97 (2): 322-338.

Dinesen, Peter T. (2011). Me and Jasmina Down by the Schoolyard: An Analysis of the Impact of Ethnic Diversity in School on the Trust of Schoolchildren. Social Science Research, 40(2), 572585.

Eger, Maureen A. 2010. Even in Sweden: The Effect of Immigration on Support for Welfare State Spending. European Sociological Review 26 (2): 203-217.

Enders, Craig K. 2010. Applied Missing Data Analysis. New York: Guilford Press.

Friedrichs, J., \& Triemer, S. 2008. Gespaltene Städte? Soziale und ethnische Segregation in deutschen Großstädten. Wiesbaden: VS Verlag für Sozialwissenschaften. 
Garofolo, James. 1981. The Fear of Crime - Causes and Consequences. Journal of Criminal Law \& Criminology 72(2): 839-857.

Gesthuizen, Maurice, Tom van der Meer, and Peer Scheepers. 2008. Ethnic Diversity and Social Capital in Europe: Tests of Putnam's Thesis in European Countries. Scandinavian Political Studies 32 (2): 121-142.

Graham, John W., Allison E. Olchowski, and Tamika D. Gilreath. 2007. How Many Imputations Are Really Needed? Some Practical Clarifications of Multiple Imputation Theory. Prevention Science 8 (3): 206-213.

Gundelach, Birte, and Richard Traunmüller. 2013. Beyond Generalized Trust: Norms of Reciprocity as an Alterntive Form of Social Capital in an Assimilationist Integration Regime. Political Studies. Doi: 10.1111/1467-9248.12064

Habyarimana, James, Macartan Humphreys, Daniel N. Posner, and Jeremy M. Weinstein. 2007. Why Does Ethnic Diversity Undermine Public Goods Provision? American Political Science Review 101 (4): 709-725.

Helbling, Marc, Tim Reeskens, and Dietlind Stolle. 2013. Bringing Political Parties Back In. Cultural Diversity, Social Cohesion and Political Mobilization. Political Studies. Doi: 10.1111/14679248.12087

Herda, Daniel. 2010. How Many Immigrants? Public Opinion Quarterly 74 (4): 674 -695.

Hooghe, Marc. 2007. Social Capital and Diversity Generalized Trust, Social Cohesion and Regimes of Diversity. Canadian Journal of Political Science/Revue Canadienne de Science Politique 40 (3): 709-732.

Hooghe, Marc, and Thomas de Vroome. 2013. The Perception of Ethnic Diversity and AntiImmigrant Sentiments: A Multilevel Analysis of Local Communities in Belgium. Ethnic and Racial Studies 38(1): 38-56.

Hopkins, Daniel J. 2010. Politicized Places: Explaining Where and When Immigrants Provoke Local Opposition. American Political Science Review 104 (1): 40-60.

Hou, Feng, and Zheng Wu. 2009. Racial Diversity, Minority Concentration, and Trust in Canadian Urban Neighborhoods. Social Science Research 38 (3): 693-716.

Jeffreys, Mark. 2008. How Can 'Cheap Talk' Yield Coordination, Given a Conflict? Mind \& Society 7 (1): 95-108.

Kesler, Christel, and Irene Bloemraad. 2010. Does Immigration Erode Social Capital? The Conditional Effects of Immigration-generated Diversity on Trust, Membership, and Participation Across 19 Countries, 1981-2000. Canadian Journal of Political Science/Revue Canadienne de Science Politique 43 (02): 319-347.

Kimenyi, Mwangi S. 2006. Ethnicity, Governance and the Provision of Public Goods. Journal African Economics 15 (1): 62-99.

Kooij-de Bode, Hanneke J. M., Daan van Knippenberg, and Wendy P. van Ginkel. 2008. Ethnic Diversity and Distributed Information in Group Decision Making: The Importance of Information Elaboration. Group Dynamics: Theory, Research, and Practice 12 (4): 307-320.

Koopmans, Ruud, Ines Michalowski, and Stine Waibel. 2012. Citizenship Rights for Immigrants. National Paths and Cross-National Convergence in Western Europe, 1980-2008. American Journal of Sociology 117 (4): 1202-1245. 
Koopmans, Ruud, and Susanne Veit. 2014. Ethnic Diversity, Trust, and the Mediating Role of Positive and Negative Interethnic Contact: A Priming Experiment. Social Science Research 47: 91-107.

Koster, Ferry (2013). Sociality in Diverse Societies: A Regional Analysis Across European Countries. Social Indicators Research, 111(2), 579-601.

Kouvo, A., and C. Lockmer. 2013. Imagine All the Neighbours: Perceived Neighbourhood Ethnicity, Interethnic Friendship Ties and Perceived Ethnic Threat in Four Nordic Countries. Urban Studies. doi:10.1177/0042098013484538.

Lancee, Bram, and Jaap Dronkers. 2011. Ethnic, Religious and Economic Diversity in Dutch Neighbourhoods: Explaining Quality of Contact with Neighbours, Trust in the Neighbourhood and Inter-Ethnic Trust. Journal of Ethnic and Migration Studies 37 (4): 597-618.

Laurence, James. 2011. The Effect of Ethnic Diversity and Community Disadvantage on Social Cohesion: A Multi-Level Analysis of Social Capital and Interethnic Relations in UK Communities. European Sociological Review 27 (1): 70-89.

Marschall, Melissa J, and Dietlind Stolle. 2004. Race and the City: Neighbourhood Context and the Development of Generalized Trust. Political Behaviour 26 (2): 125-153.

Mata, Fernando and Pendakur, Ravi (2014). Social Capital, Diversity and Giving or Receiving Help Among Neighbours. Social Indicators Research, 118(1), 329-347.

Page, Scott E. 2008. The Difference: How the Power of Diversity Creates Better Groups, Firms, Schools, and Societies. Princeton: Princeton University Press.

Putnam, Robert D. 2007. E Pluribus Unum: Diversity and Community in the Twenty-First Century. Scandinavian Political Studies 30 (2): 137-174.

Ruttan, Lore M. 2006. Sociocultural Heterogeneity and the Commons. Current Anthropology 47 (5): 843-853. doi:10.1086/507185.

Sampson, Robert J., Jeffrey D. Morenoff, and Felton Earls. 1999. Beyond Social Capital: Spatial Dynamics of Collective Efficacy for Children. American Sociological Review 64 (5): 633-660.

Schaeffer, Merlin. 2014. Ethnic Diversity and Social Cohesion: Immigration, Ethnic Fractionalization and Potentials for Civic Action. Aldershot: Ashgate.

2013. Can Competing Diversity Indices Inform Us About Why Ethnic Diversity Erodes Social Cohesion? A Test of Five Diversity Indices in Germany. Social Science Research 42 (3): 755-774.

Schaeffer, Merlin, Ruud Koopmans, Susanne Veit, Mareike Wagner, and Jonas Wiedner. 2011. The Ethnic Diversity and Collective Action Survey (EDCAS). WZB Discussion Paper Series No. SP IV 2011-701.

Schlueter, Elmar, and Eldad Davidov. 2011. Contextual Sources of Perceived Group Threat: Negative Immigration-Related News Reports, Immigrant Group Size and Their Interaction, Spain 19962007. European Sociological Review 29 (2): 179-191.

Schlueter, Elmar, and Peer Scheepers. 2010. The Relationship Between Outgroup Size and AntiOutgroup Attitudes: A Theoretical Synthesis and Empirical Test of Group Threat-and Intergroup Contact Theory. Social Science Research 39(2): 285-295.

Semyonov, Moshe, Rebeca Raijman, and Anastasia Gorodzeisky. 2008. Foreigners' Impact on European Societies: Public Views and Perceptions in a Cross-National Comparative Perspective. International Journal of Comparative Sociology 49 (1): 5-29. 
Sigelman, Lee, and Richard G. Niemi. 2001. Innumeracy About Minority Populations: African Americans and Whites Compared. The Public Opinion Quarterly 65 (1): 86-94.

Stichnoth, Holger. 2012. Does Immigration Weaken Natives' Support for the Unemployed? Evidence from Germany. Public Choice 151 (3): 631-654.

Stolle, Dietlind, Stuart Soroka, and R. Johnston. 2008. When Does Diversity Erode Trust? Neighborhood Diversity, Interpersonal Trust and the Mediating Effect of Social Interactions. Political Studies 56 (1): 57-75.

Swidler, Ann. 1986. Culture in Action - Symbols and Strategies. American Sociological Review 51 (2): 273-286.

Tajfel, Henri. 1978. Social Categorization, Social Identity and Social Comparison. In Differentiation Between Social Groups, edited by Henri Tajfel, 61:61 - 76. London: Academic Press.

Tajfel, Henri, and John C. Turner. 1986. The Social Identity Theory of Intergroup Behavior. In Psychology of Intergroup Relations, edited by Stephen Worchel and William G. Austin, 7 - 24. Chicago: Nelson-Hall Publishers.

Tolsma, Jochem, Tom van der Meer, and Maurice Gesthuizen. 2009. The Impact of Neighbourhood and Municipality Characteristics on Social Cohesion in the Netherlands. Acta Politica 44 (3): 286313.

Van der Meer, Tom, and Jochem Tolsma. 2014. Ethnic Diversity and Its Supposed Detrimental Effects on Social Cohesion Annual Review of Sociology (40). Doi: 10.1146/annurev-soc-071913043309 .

Vanparys, Nathalie, Dirk Jacobs, and Corinne Torrekens. 2013. The Impact of Dramatic Events on Public Debate Concerning Accommodation of Islam in Europe. Ethnicities 13 (2): 209-228.

Wong, Cara J. 2007. 'Little' and 'Big' Pictures in Our Heads: Race, Local Context, and Innumeracy About Racial Groups in the United States. Public Opininion Quarterly 71 (3): 392-412.

Wooldridge, Jeffrey M. 2003. Cluster-Sample Methods in Applied Econometrics. The American Economic Review 93 (2): 133-138.

$\mathrm{Xu}$, Yili, Mora L. Fiedler, and Karl H. Flaming. 2005. Discovering the Impact of Community Policing: The Broken Windows Thesis, Collective Efficacy, and Citizens' Judgment. Journal of Research in Crime and Delinquency 42(2): 147-186.

Zhang, Zhen, Michael J. Zyphur, and Kristopher J. Preacher. 2009. Testing Multilevel Mediation Using Hierarchical Linear Models. Organizational Research Methods 12 (4): 695 -719. 
Table A1: The 27 Cities and Regions Included in the Analysis

\begin{tabular}{|c|c|}
\hline Region & Type \\
\hline \multicolumn{2}{|c|}{ Germany } \\
\hline Berlin & City \\
\hline Bremen & City \\
\hline Duisburg & City \\
\hline Frankfurt am Main & City \\
\hline Hamburg & City \\
\hline Köln & City \\
\hline München & City \\
\hline Offenbach am Main & City \\
\hline \multicolumn{2}{|c|}{ France } \\
\hline Dordogne & Département \\
\hline Hauts de Seine & $\begin{array}{l}\text { Urban département } \\
\text { (Paris agglomeration) }\end{array}$ \\
\hline Lille & Commune \\
\hline Lyons & Commune \\
\hline Marseille & Commune \\
\hline Paris & $\begin{array}{l}\text { Urban département } \\
\text { (Paris agglomeration) }\end{array}$ \\
\hline Rennes & Commune \\
\hline Seine St. Denis & $\begin{array}{l}\text { Urban département } \\
\text { (Paris agglomeration) }\end{array}$ \\
\hline Strasbourg & Commune \\
\hline Val de Marne & $\begin{array}{l}\text { Urban département } \\
\text { (Paris agglomeration) }\end{array}$ \\
\hline \multicolumn{2}{|c|}{ Netherlands } \\
\hline Amsterdam & Municipality \\
\hline Arnhem & Municipality \\
\hline Den Haag & Municipality \\
\hline Eindhoven & Municipality \\
\hline Flevoland & Province \\
\hline Friesland & Province \\
\hline Gouda & Municipality \\
\hline Rotterdam & Municipality \\
\hline Twente & Region \\
\hline
\end{tabular}


Table A2: Descriptive Statistics

\begin{tabular}{|c|c|c|c|c|}
\hline & Mean & SD & Min & Max \\
\hline \multicolumn{5}{|c|}{ Dependent Variables } \\
\hline Trust & 6.48 & 2.40 & 0 & 10 \\
\hline Collective Efficacy & 5.80 & 2.58 & 0 & 10 \\
\hline Connectedness & 6.24 & 2.57 & 0 & 10 \\
\hline Satisfaction & 7.38 & 1.95 & 0 & 10 \\
\hline Reported Problems & 1.14 & 0.92 & 0 & 4 \\
\hline Neighborhood Cohesion Scale & 0.00 & 1.00 & -4 & 2 \\
\hline \multicolumn{5}{|c|}{ Predictor Variables } \\
\hline \multicolumn{5}{|c|}{ Neighborhood-Level } \\
\hline Proportion Persons of Immigrant Origin & 0.33 & 0.15 & 0 & 0.90 \\
\hline Aggregate Level & 0.30 & 0.17 & 0 & 0.90 \\
\hline Local Unemployment Rate & 0.12 & 0.07 & 0 & 0.40 \\
\hline Aggregate Level & 0.10 & 0.07 & 0 & 0.40 \\
\hline Population Density & 6.70 & 5.03 & 0 & 26.32 \\
\hline Aggregate Level & 5.66 & 5.53 & 0 & 26.32 \\
\hline \multicolumn{5}{|c|}{ Individual-Level } \\
\hline Perceived Numeric Diversity & 33.85 & 25.95 & 0 & 100 \\
\hline Perceived Intergroup Conflict & 0.89 & 0.97 & 0 & 4 \\
\hline Perceived Linguistic Diversity & 4.04 & 3.03 & 0 & 10 \\
\hline Perceived Preference Diversity & 5.03 & 2.51 & 0 & 10 \\
\hline Perceived Socio-Economic Diversity & 5.33 & 2.44 & 0 & 10 \\
\hline Age (in 10 years) & 4.80 & 1.71 & 2 & 9 \\
\hline Low Education & 0.16 & 0.37 & 0 & 1 \\
\hline Medium Education & 0.45 & 0.50 & 0 & 1 \\
\hline High Education & 0.39 & 0.49 & 0 & 1 \\
\hline Employed & 0.58 & 0.49 & 0 & 1 \\
\hline Residence in the Neighborhood (in 10 years) & 1.76 & 1.51 & 0 & 9 \\
\hline Home Owner & 0.42 & 0.49 & 0 & 1 \\
\hline Female & 0.55 & 0.50 & 0 & 1 \\
\hline Immigrant Origin & 0.49 & 0.50 & 0 & 1 \\
\hline Married & 0.47 & 0.50 & 0 & 1 \\
\hline Atheist & 0.40 & 0.49 & 0 & 1 \\
\hline Protestant & 0.10 & 0.31 & 0 & 1 \\
\hline Catholic & 0.21 & 0.41 & 0 & 1 \\
\hline Muslim & 0.18 & 0.39 & 0 & 1 \\
\hline Other Religion & 0.10 & 0.29 & 0 & 1 \\
\hline
\end{tabular}


Table A3: Statistical and Perceived Diversity as a Predictor of Neighborhood Social Cohesion across 228 German Neighborhoods

\begin{tabular}{|c|c|c|c|}
\hline & $(1)$ & (2) & (3) \\
\hline \multicolumn{4}{|c|}{ Neighborhood level } \\
\hline \multirow{2}{*}{ Statistical Ethnic Diversity } & $-0.156^{* * *}$ & $-0.114^{* *}$ & -0.064 \\
\hline & $(0.042)$ & $(0.039)$ & $(0.040)$ \\
\hline \multirow[t]{2}{*}{ Local Unemployment Rate } & $-0.062^{*}$ & -0.043 & -0.034 \\
\hline & $(0.028)$ & $(0.026)$ & $(0.025)$ \\
\hline \multirow[t]{2}{*}{ Population Density } & 0.009 & 0.008 & 0.001 \\
\hline & $(0.035)$ & $(0.032)$ & $(0.032)$ \\
\hline \multicolumn{4}{|c|}{ Individual level } \\
\hline \multirow[t]{2}{*}{ Age (in 10 years) } & $0.110^{* *}$ & 0.048 & 0.027 \\
\hline & $(0.036)$ & $(0.034)$ & $(0.033)$ \\
\hline Education, reference: Low & ref. & ref. & ref. \\
\hline \multirow[t]{2}{*}{ Medium } & 0.002 & 0.007 & 0.009 \\
\hline & $(0.093)$ & $(0.086)$ & $(0.086)$ \\
\hline \multirow[t]{2}{*}{ High } & 0.049 & 0.072 & 0.067 \\
\hline & $(0.102)$ & $(0.094)$ & $(0.093)$ \\
\hline \multirow[t]{2}{*}{ Employed } & 0.079 & 0.078 & 0.071 \\
\hline & $(0.051)$ & $(0.049)$ & $(0.047)$ \\
\hline \multirow[t]{2}{*}{ Residence in the Neighborhood (in 10 years) } & 0.044 & 0.041 & 0.042 \\
\hline & $(0.030)$ & $(0.028)$ & $(0.028)$ \\
\hline \multirow[t]{2}{*}{ Home Owner } & $0.370^{* * *}$ & $0.324^{* * *}$ & $0.304^{* * *}$ \\
\hline & $(0.049)$ & $(0.050)$ & $(0.049)$ \\
\hline \multirow[t]{2}{*}{ Female } & $0.138^{* *}$ & $0.099^{*}$ & $0.120^{*}$ \\
\hline & $(0.051)$ & $(0.047)$ & $(0.047)$ \\
\hline \multirow[t]{2}{*}{ Married } & $0.176^{* * *}$ & $0.173^{* * *}$ & $0.171^{* * *}$ \\
\hline & $(0.048)$ & $(0.046)$ & $(0.045)$ \\
\hline \multirow[t]{2}{*}{ Immigrant Origin } & 0.017 & 0.046 & 0.053 \\
\hline & $(0.057)$ & $(0.056)$ & $(0.055)$ \\
\hline Religion, reference: Atheist & ref. & ref. & ref. \\
\hline \multirow[t]{2}{*}{ Protestant } & 0.080 & 0.095 & 0.110 \\
\hline & $(0.064)$ & $(0.060)$ & $(0.058)$ \\
\hline \multirow[t]{2}{*}{ Catholic } & 0.089 & 0.104 & $0.131^{*}$ \\
\hline & $(0.064)$ & $(0.060)$ & $(0.059)$ \\
\hline \multirow[t]{2}{*}{ Muslim } & 0.077 & 0.106 & 0.169 \\
\hline & $(0.095)$ & $(0.093)$ & $(0.092)$ \\
\hline \multirow[t]{2}{*}{ Other } & -0.060 & -0.028 & -0.031 \\
\hline & $(0.091)$ & $(0.088)$ & $(0.086)$ \\
\hline \multirow{2}{*}{\multicolumn{2}{|c|}{ Perceived Linguistic Diversity }} & $-0.164^{* * *}$ & $-0.080^{*}$ \\
\hline & & $(0.030)$ & $(0.031)$ \\
\hline \multirow[t]{2}{*}{ Perceived Preference Diversity } & & $-0.099^{* *}$ & $-0.092^{* *}$ \\
\hline & & $(0.032)$ & $(0.032)$ \\
\hline Perceived Intergroup Conflict & & $-0.167^{* * *}$ & $-0.163^{* * *}$ \\
\hline & & $(0.026)$ & $(0.025)$ \\
\hline Perceived Socio-Economic Diversity & & $0.069^{*}$ & $0.067^{*}$ \\
\hline & & $(0.031)$ & $(0.030)$ \\
\hline Perceived Numeric Diversity & & & $-0.211^{* * *}$ \\
\hline & & & $(0.033)$ \\
\hline Constant & $-0.278^{*}$ & $-0.294^{* *}$ & $-0.332^{* *}$ \\
\hline & $(0.114)$ & $(0.102)$ & $(0.101)$ \\
\hline Observations & 1955 & 1955 & 1955 \\
\hline Adjusted R-squared & 0.104 & 0.165 & 0.186 \\
\hline
\end{tabular}


Table A4: Statistical and Perceived Diversity as a Predictor of Neighborhood Social Cohesion Across 495 Dutch Neighborhoods

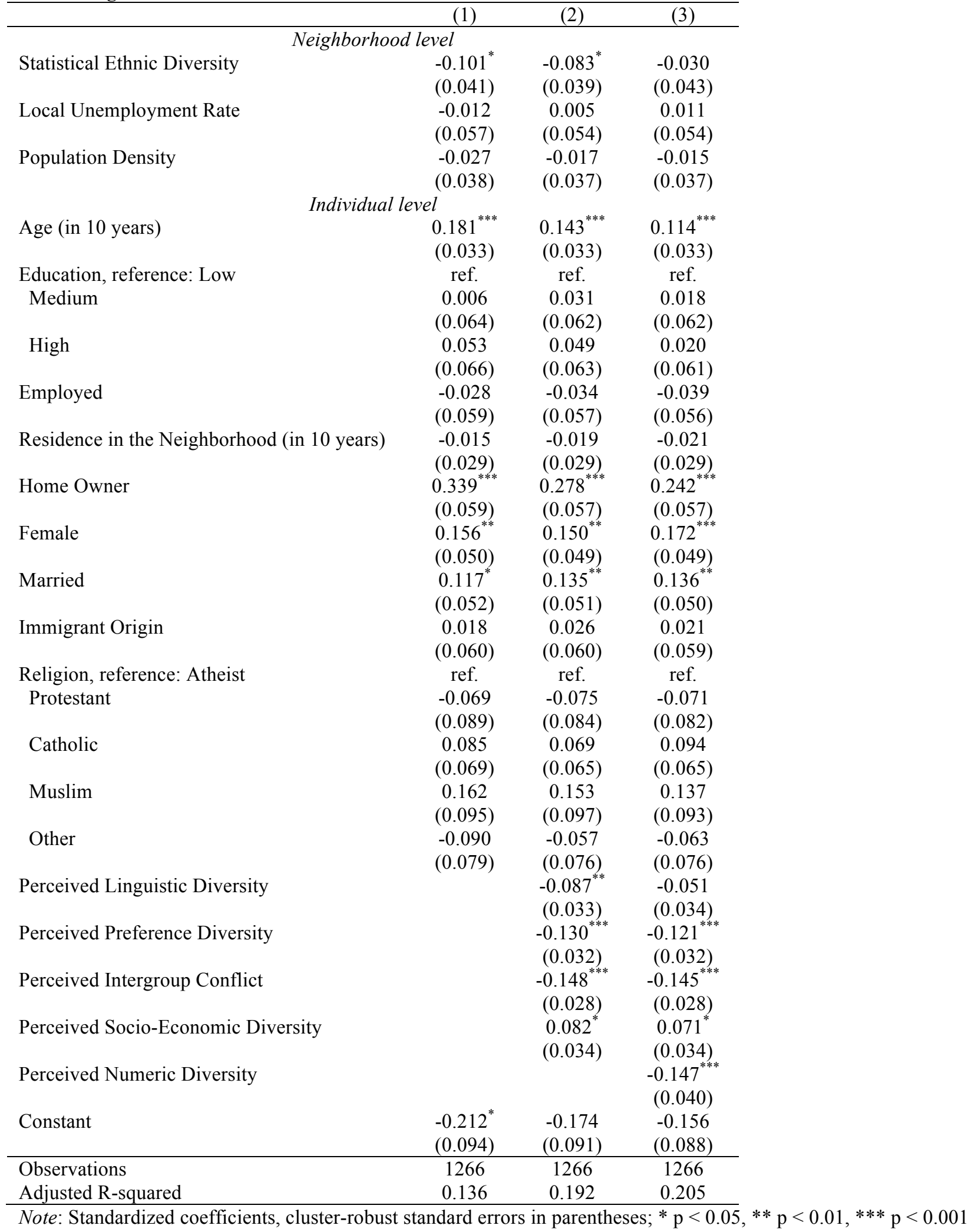


Table A5: Statistical and Perceived Diversity as a Predictor of Neighborhood Social Cohesion Across 215 French Neighborhoods

\begin{tabular}{|c|c|c|c|}
\hline & (1) & (2) & (3) \\
\hline \multicolumn{4}{|c|}{ Neighborhood level } \\
\hline \multirow[t]{2}{*}{ Statistical Ethnic Diversity } & $-0.118^{* *}$ & $-0.103^{* *}$ & -0.057 \\
\hline & $(0.036)$ & $(0.036)$ & $(0.039)$ \\
\hline \multirow[t]{2}{*}{ Local Unemployment Rate } & $-0.312^{* * *}$ & $-0.295^{* * *}$ & $-0.257^{* *}$ \\
\hline & $(0.075)$ & $(0.078)$ & $(0.079)$ \\
\hline \multirow[t]{2}{*}{ Population Density } & -0.011 & -0.015 & -0.014 \\
\hline & $(0.022)$ & $(0.022)$ & $(0.022)$ \\
\hline \multicolumn{4}{|c|}{ Individual level } \\
\hline \multirow[t]{2}{*}{ Age (in 10 years) } & 0.041 & 0.025 & -0.002 \\
\hline & $(0.034)$ & $(0.033)$ & $(0.034)$ \\
\hline Education, reference: Low & ref. & ref. & ref. \\
\hline \multirow[t]{2}{*}{ Medium } & -0.120 & -0.161 & -0.166 \\
\hline & $(0.096)$ & $(0.092)$ & $(0.089)$ \\
\hline \multirow[t]{2}{*}{ High } & -0.018 & -0.083 & -0.101 \\
\hline & $(0.095)$ & $(0.094)$ & $(0.091)$ \\
\hline \multirow[t]{2}{*}{ Employed } & 0.088 & 0.094 & 0.098 \\
\hline & $(0.054)$ & $(0.053)$ & $(0.052)$ \\
\hline \multirow[t]{2}{*}{ Residence in the Neighborhood (in 10 years) } & $0.089^{* *}$ & $0.084^{* *}$ & $0.097^{* *}$ \\
\hline & $(0.033)$ & $(0.032)$ & $(0.031)$ \\
\hline \multirow[t]{2}{*}{ Home Owner } & $0.249^{* * *}$ & $0.235^{* * *}$ & $0.190^{* * *}$ \\
\hline & $(0.058)$ & $(0.056)$ & $(0.056)$ \\
\hline \multirow[t]{2}{*}{ Female } & 0.101 & $0.110^{*}$ & $0.129^{* *}$ \\
\hline & $(0.052)$ & $(0.050)$ & $(0.049)$ \\
\hline \multirow[t]{2}{*}{ Married } & 0.076 & 0.060 & 0.046 \\
\hline & $(0.062)$ & $(0.062)$ & $(0.062)$ \\
\hline \multirow[t]{2}{*}{ Immigrant Origin } & 0.020 & 0.020 & 0.050 \\
\hline & $(0.060)$ & $(0.059)$ & $(0.057)$ \\
\hline Religion, reference: Atheist & ref. & ref. & ref. \\
\hline \multirow[t]{2}{*}{ Protestant } & 0.021 & -0.010 & -0.052 \\
\hline & $(0.151)$ & $(0.145)$ & $(0.144)$ \\
\hline \multirow[t]{2}{*}{ Catholic } & 0.064 & 0.076 & 0.086 \\
\hline & $(0.062)$ & $(0.060)$ & $(0.058)$ \\
\hline \multirow[t]{2}{*}{ Muslim } & -0.006 & 0.012 & 0.061 \\
\hline & $(0.093)$ & $(0.096)$ & $(0.091)$ \\
\hline \multirow[t]{2}{*}{ Other } & 0.048 & 0.077 & 0.098 \\
\hline & $(0.105)$ & $(0.102)$ & $(0.102)$ \\
\hline \multirow{2}{*}{\multicolumn{2}{|c|}{ Perceived Linguistic Diversity }} & $-0.116^{* * * *}$ & $-0.065^{*}$ \\
\hline & & $(0.031)$ & $(0.031)$ \\
\hline \multirow{2}{*}{\multicolumn{2}{|c|}{ Perceived Preference Diversity }} & -0.004 & -0.011 \\
\hline & & $(0.036)$ & $(0.036)$ \\
\hline Perceived Intergroup Conflict & & $-0.138^{* * *}$ & $-0.130^{* * *}$ \\
\hline & & $(0.026)$ & $(0.025)$ \\
\hline Perceived Socio-Economic Diversity & & 0.013 & 0.009 \\
\hline & & $(0.032)$ & $(0.031)$ \\
\hline Perceived Numeric Diversity & & & $-0.168^{* * *}$ \\
\hline & & & $(0.038)$ \\
\hline Constant & $-0.536^{* * *}$ & $-0.492^{* * *}$ & $-0.470^{* * *}$ \\
\hline & $(0.105)$ & $(0.106)$ & $(0.105)$ \\
\hline Observations & 1406 & 1406 & 1406 \\
\hline Adjusted R-squared & 0.088 & 0.116 & 0.135 \\
\hline
\end{tabular}


Table A6: Statistical Diversity as a Predictor of Neighborhood Social Cohesion Among Natives Across 938 German, Dutch and French Neighborhoods

\begin{tabular}{|c|c|c|c|}
\hline & (1) & (2) & (3) \\
\hline \multicolumn{4}{|c|}{ Neighborhood level } \\
\hline \multirow[t]{2}{*}{ Statistical Ethnic Diversity } & $-0.152^{* * *}$ & $-0.094^{* * *}$ & -0.025 \\
\hline & $(0.027)$ & $(0.026)$ & $(0.026)$ \\
\hline \multirow[t]{2}{*}{ Local Unemployment Rate } & $-0.073^{* *}$ & -0.050 & -0.044 \\
\hline & $(0.027)$ & $(0.026)$ & $(0.026)$ \\
\hline \multirow[t]{2}{*}{ Population Density } & -0.009 & -0.017 & -0.014 \\
\hline & $(0.020)$ & $(0.019)$ & $(0.019)$ \\
\hline Country, reference: Germany & ref. & ref. & ref. \\
\hline \multirow[t]{2}{*}{ The Netherlands } & -0.080 & -0.020 & -0.008 \\
\hline & $(0.052)$ & $(0.051)$ & $(0.052)$ \\
\hline \multirow[t]{3}{*}{ France } & $-0.458^{* * *}$ & $-0.398^{* * *}$ & $-0.362^{* * *}$ \\
\hline & $(0.058)$ & $(0.054)$ & $(0.052)$ \\
\hline & & & \\
\hline \multirow[t]{2}{*}{ Age (in 10 years) } & $0.127^{* * *}$ & $0.070^{* *}$ & 0.048 \\
\hline & $(0.027)$ & $(0.026)$ & $(0.025)$ \\
\hline Education, reference: Low & ref. & ref. & ref. \\
\hline \multirow[t]{2}{*}{ Medium } & 0.014 & -0.033 & -0.048 \\
\hline & $(0.066)$ & $(0.063)$ & $(0.061)$ \\
\hline \multirow[t]{2}{*}{ High } & 0.075 & 0.022 & -0.014 \\
\hline & $(0.066)$ & $(0.064)$ & $(0.063)$ \\
\hline \multirow[t]{2}{*}{ Employed } & 0.056 & 0.045 & 0.046 \\
\hline & $(0.044)$ & $(0.043)$ & $(0.042)$ \\
\hline \multirow[t]{2}{*}{ Residence in the Neighborhood (in 10 years) } & 0.009 & 0.010 & 0.013 \\
\hline & $(0.022)$ & $(0.021)$ & $(0.021)$ \\
\hline \multirow[t]{2}{*}{ Home Owner } & $0.292^{* * * *}$ & $0.245^{* * *}$ & $0.207^{* * *}$ \\
\hline & $(0.039)$ & $(0.037)$ & $(0.036)$ \\
\hline \multirow[t]{2}{*}{ Female } & $0.182^{* * *}$ & $0.150^{* * *}$ & $0.186^{* * *}$ \\
\hline & $(0.039)$ & $(0.038)$ & $(0.038)$ \\
\hline \multirow[t]{2}{*}{ Married } & $0.106^{*}$ & $0.104^{* *}$ & $0.097^{*}$ \\
\hline & $(0.042)$ & $(0.039)$ & $(0.039)$ \\
\hline Religion, reference: Atheist & ref. & ref. & ref. \\
\hline \multirow[t]{2}{*}{ Protestant } & 0.021 & 0.020 & 0.026 \\
\hline & $(0.054)$ & $(0.052)$ & $(0.050)$ \\
\hline \multirow[t]{2}{*}{ Catholic } & 0.052 & 0.072 & 0.083 \\
\hline & $(0.048)$ & $(0.046)$ & $(0.045)$ \\
\hline \multirow[t]{2}{*}{ Other } & -0.140 & -0.093 & -0.084 \\
\hline & $(0.080)$ & $(0.075)$ & $(0.073)$ \\
\hline \multirow{2}{*}{\multicolumn{2}{|c|}{ Perceived Linguistic Diversity }} & $-0.173^{* * *}$ & $-0.089^{* * *}$ \\
\hline & & $(0.025)$ & $(0.025)$ \\
\hline Perceived Preference Diversity & & $-0.084^{* *}$ & $-0.077^{* *}$ \\
\hline & & $(0.026)$ & $(0.026)$ \\
\hline Perceived Intergroup Conflict & & $-0.153^{* * *}$ & $-0.133^{* * *}$ \\
\hline & & $(0.021)$ & $(0.020)$ \\
\hline Perceived Socio-Economic Diversity & & $0.061^{*}$ & $0.062^{*}$ \\
\hline & & $(0.026)$ & $(0.026)$ \\
\hline Perceived Numeric Diversity & & & $-0.238^{* * *}$ \\
\hline & & & $(0.029)$ \\
\hline Constant & $-0.215^{* *}$ & $-0.175^{*}$ & $-0.193^{*}$ \\
\hline & $(0.082)$ & $(0.080)$ & $(0.079)$ \\
\hline Observations & 2373 & 2373 & 2373 \\
\hline Adjusted R-squared & 0.140 & 0.206 & 0.234 \\
\hline
\end{tabular}


Table A7: Statistical Diversity as a Predictor of Neighborhood Social Cohesion Among Persons of Immigrant origin Across 938 German, Dutch and French Neighborhoods

\begin{tabular}{|c|c|c|c|}
\hline & (1) & $(2)$ & (3) \\
\hline \multicolumn{4}{|c|}{ Neighborhood level } \\
\hline \multirow[t]{2}{*}{ Statistical Ethnic Diversity } & $-0.104^{* *}$ & $-0.099^{* *}$ & -0.055 \\
\hline & $(0.032)$ & $(0.032)$ & $(0.033)$ \\
\hline \multirow[t]{2}{*}{ Local Unemployment Rate } & $-0.081^{*}$ & $-0.066^{*}$ & -0.056 \\
\hline & $(0.035)$ & $(0.033)$ & $(0.032)$ \\
\hline \multirow[t]{2}{*}{ Population Density } & 0.030 & 0.032 & 0.030 \\
\hline & $(0.026)$ & $(0.026)$ & $(0.026)$ \\
\hline \multirow{3}{*}{$\begin{array}{l}\text { Country, reference: Germany } \\
\text { The Netherlands }\end{array}$} & ref. & ref. & ref. \\
\hline & -0.064 & -0.040 & -0.034 \\
\hline & $(0.073)$ & $(0.071)$ & $(0.071)$ \\
\hline \multirow[t]{2}{*}{ France } & $-0.481^{* * *}$ & $-0.491^{* * * *}$ & $-0.438^{* * *}$ \\
\hline & $(0.063)$ & $(0.064)$ & $(0.062)$ \\
\hline \multicolumn{4}{|c|}{ Individual level } \\
\hline \multirow[t]{2}{*}{ Age (in 10 years) } & $0.088^{* *}$ & $0.076^{*}$ & 0.050 \\
\hline & $(0.031)$ & $(0.031)$ & $(0.031)$ \\
\hline \multirow{3}{*}{$\begin{array}{l}\text { Education, reference: Low } \\
\text { Medium }\end{array}$} & ref. & ref. & ref. \\
\hline & -0.074 & -0.071 & -0.074 \\
\hline & $(0.067)$ & $(0.064)$ & $(0.063)$ \\
\hline \multirow[t]{2}{*}{ High } & 0.005 & -0.009 & -0.017 \\
\hline & $(0.071)$ & $(0.069)$ & $(0.068)$ \\
\hline \multirow[t]{2}{*}{ Employed } & 0.031 & 0.039 & 0.036 \\
\hline & $(0.046)$ & $(0.045)$ & $(0.044)$ \\
\hline \multirow[t]{2}{*}{ Residence in the Neighborhood (in 10 years) } & $0.098^{* *}$ & $0.090^{* *}$ & $0.094^{* *}$ \\
\hline & $(0.030)$ & $(0.030)$ & $(0.029)$ \\
\hline \multirow[t]{2}{*}{ Home Owner } & $0.343^{* * *}$ & $0.315^{* * *}$ & $0.283^{* * *}$ \\
\hline & $(0.047)$ & $(0.048)$ & $(0.047)$ \\
\hline \multirow[t]{2}{*}{ Female } & $0.091^{*}$ & $0.102^{*}$ & $0.114^{* *}$ \\
\hline & $(0.044)$ & $(0.043)$ & $(0.042)$ \\
\hline \multirow[t]{2}{*}{ Married } & $0.159^{* * *}$ & $0.150^{* *}$ & $0.146^{* *}$ \\
\hline & $(0.047)$ & $(0.047)$ & $(0.045)$ \\
\hline & ref. & ref. & ref. \\
\hline \multirow[t]{2}{*}{ Protestant } & 0.093 & 0.100 & 0.108 \\
\hline & $(0.097)$ & $(0.093)$ & $(0.089)$ \\
\hline \multirow[t]{2}{*}{ Catholic } & 0.099 & 0.096 & 0.115 \\
\hline & $(0.063)$ & $(0.061)$ & $(0.060)$ \\
\hline \multirow[t]{2}{*}{ Muslim } & 0.073 & 0.091 & 0.115 \\
\hline & $(0.060)$ & $(0.060)$ & $(0.059)$ \\
\hline \multirow[t]{2}{*}{ Other } & 0.014 & 0.042 & 0.043 \\
\hline & $(0.074)$ & $(0.073)$ & $(0.073)$ \\
\hline Perceived Linguistic Diversity & & $-0.087^{* *}$ & -0.044 \\
\hline & & $(0.028)$ & $(0.028)$ \\
\hline Perceived Preference Diversity & & $-0.068^{*}$ & $-0.067^{*}$ \\
\hline & & $(0.029)$ & $(0.029)$ \\
\hline Perceived Intergroup Conflict & & $-0.147^{* * * *}$ & $-0.149^{* * *}$ \\
\hline & & $(0.023)$ & $(0.023)$ \\
\hline Perceived Socio-Economic Diversity & & 0.043 & 0.034 \\
\hline & & $(0.028)$ & $(0.028)$ \\
\hline Perceived Numeric Diversity & & & $-0.136^{* * *}$ \\
\hline & & & $(0.029)$ \\
\hline Constant & -0.126 & -0.113 & -0.124 \\
\hline & $(0.090)$ & $(0.085)$ & $(0.084)$ \\
\hline Observations & 2254 & 2254 & 2254 \\
\hline Adjusted R-squared & 0.098 & 0.129 & 0.141 \\
\hline
\end{tabular}


Table A8: Country differences in Statistical Diversity as a Predictor of Neighborhood Social Cohesion with Neighborhood Fixed Effects

\begin{tabular}{|c|c|}
\hline & (1) \\
\hline Perceived Socio-Economic Diversity & $\begin{array}{c}0.062 \\
(0.032)\end{array}$ \\
\hline$* \mathrm{NL}$ & $\begin{array}{c}0.010 \\
(0.023)\end{array}$ \\
\hline *FR & $\begin{array}{l}-0.024 \\
(0.019)\end{array}$ \\
\hline Perceived Preference Diversity & $\begin{array}{c}-0.097^{* *} \\
(0.032)\end{array}$ \\
\hline$* \mathrm{NL}$ & $\begin{array}{c}-0.003 \\
(0.021)\end{array}$ \\
\hline *FR & $\begin{array}{c}0.036 \\
(0.020)\end{array}$ \\
\hline Perceived Linguistic Diversity & $\begin{array}{l}-0.067^{*} \\
(0.033)\end{array}$ \\
\hline$* \mathrm{NL}$ & $\begin{array}{c}0.008 \\
(0.019)\end{array}$ \\
\hline$* \mathrm{FR}$ & $\begin{array}{c}0.006 \\
(0.016)\end{array}$ \\
\hline Perceived Intergroup Conflict & $\begin{array}{c}-0.157^{* * *} \\
(0.026)\end{array}$ \\
\hline$* \mathrm{NL}$ & $\begin{array}{c}-0.002 \\
(0.043)\end{array}$ \\
\hline *FR & $\begin{array}{c}0.023 \\
(0.037)\end{array}$ \\
\hline Perceived Numeric Diversity & $\begin{array}{c}-0.235^{* * *} \\
(0.034)\end{array}$ \\
\hline$* \mathrm{NL}$ & $\begin{array}{c}0.004 \\
(0.002)\end{array}$ \\
\hline *FR & $\begin{array}{c}0.003 \\
(0.002)\end{array}$ \\
\hline Control variables & Yes \\
\hline Observations & 4627 \\
\hline
\end{tabular}

Note: Fixed-effects robust standard errors in parentheses; $* \mathrm{p}<0.05, * * \mathrm{p}<0.01, * * * \mathrm{p}<0.001$. These results are adjusted for: the number of years someone has lived in the neighborhood, home ownership, education, age, gender, marital status, employment status, immigrant origin and religious confession 
Table A9: Differences in Perceived Socio-Economic Diversity as a Predictor of Neighborhood Social Cohesion by Education

\begin{tabular}{|c|c|}
\hline & Neighborhood Cohesion Scale \\
\hline Perceived Socio-Economic Diversity & $\begin{array}{c}0.042 \\
(0.028)\end{array}$ \\
\hline \multicolumn{2}{|l|}{ Education, reference: medium } \\
\hline Low & $\begin{array}{l}-0.081 \\
(0.126)\end{array}$ \\
\hline High & $\begin{array}{c}0.107 \\
(0.085)\end{array}$ \\
\hline $\begin{array}{l}\text { Low Education } \\
\quad \text { *Perceived Socio-Economic Diversity }\end{array}$ & 0.029 \\
\hline & $(0.022)$ \\
\hline $\begin{array}{l}\text { High Education } \\
\text { *Perceived Socio-Economic Diversity }\end{array}$ & -0.009 \\
\hline Perceived Linguistic Diversity & $\begin{array}{l}(0.015) \\
-0.061^{* *} \\
(0.021)\end{array}$ \\
\hline Perceived Intergroup Conflict & $\begin{array}{l}-0.153^{* * *} \\
(0.016)\end{array}$ \\
\hline Perceived Preference Diversity & $\begin{array}{l}-0.068^{* * *} \\
(0.021)\end{array}$ \\
\hline Perceived Numeric Diversity & $\begin{array}{l}-0.184^{* * *} \\
(0.023)\end{array}$ \\
\hline Control variables & Yes \\
\hline Observations & 4627 \\
\hline
\end{tabular}

